\title{
Neuroprotective and Hypoglycemic Effects of the Nanoemulsion and Nettle Aqueous Extract on Streptozotocin-Induced Diabetic Neuropathy in Rats: Molecular, Biochemical, and Histological Evidence
}

\section{Sara Javadi}

Tehran University of Medical Sciences

Majid Motaghinejad ( $\nabla$ dr.motaghinejad6@gmail.com )

Iran University of Medical Sciences: Tehran University of Medical Sciences

Negar Motakef Kazemi

Islamic Azad University Tehran Medical Sciences

Amelia Seifalian

University College London Medical School

\section{Research Article}

Keywords: Diabetes, Neuropathy, Nano emulsion, Nettle Nano emulsion and aqueous extract, Cuminum cyminum L essence

Posted Date: February 24th, 2022

DOI: https://doi.org/10.21203/rs.3.rs-1366186/v1

License: (c) (i) This work is licensed under a Creative Commons Attribution 4.0 International License. Read Full License 


\section{Abstract}

Background: Nanotechnology plays an important role in controlling diabetes.

Aim of Study: In current study, antidiabetic properties of the O/W Nano emulsion of nettle extract and cumin essential oil were evaluated.

Methods:Various doses of Nettle (Urtica dioica) aqueous extract, nettle Nano emulsion, and Cuminum cyminum $L$ essence were used in Streptozocin-induced diabetes in rats. Randall-Selitto method and Tail Flic Test were used for sciatic nerve neuropathy. Sciatic histological changes and level of Insulin like growth factor (IGF), neural growth factor (NGF), Oxidative stress, inflammatory, and apoptosis as well as blood levels of Glucose, Insulin, and inflammatory parameters were evaluated.

Results: Nettle Nano emulsion, aqueous extract, and Cuminum cyminum L essence caused decreases in serum levels of glucose and cytokines, and increased insulin level while improved histological changes and reduced sciatic levels of thiobarbituric acid, reduced glutathione (GSH), TNF-a, IL-1ß, IL-6 Bax, Bcl-2, Caspase-3, and Caspase-7, and increased the oxidized level of glutathione (GSSG) and activities of superoxide dismutase (SOD), catalase (CAT), glutathione peroxidase (GPx), and glutathione reductase (GR) and levels of IGF and NGF in the sciatic tissue of diabetic rats.

Conclusion: Nettle Nano emulsion, aqueous extract, and Cuminum cyminum $L$ essence can be a good candidates for diabetic subjects.

\section{Introduction}

Diabetes is a metabolic disorder known as one of the major health problems in human societies due to bringing numerous complications and causing high mortality (1). Diabetes is a disorder that slows down the body's ability to use and metabolize the received sugars completely, resulting in high blood sugar level in the body. Diabetes mellitus is a chronic disease occurring when the islets of the Langerhans pancreas could not produce insulin or when the body cannot use the produced insulin effectively. Stopping insulin production or not using it both raise blood glucose level and lead to its consequences (1). Many chemical drugs used in diabetes, despite their undeniable benefits, also have many destructive effects such as increasing fat stores, degeneration of adipose tissue at the injection site, and the onset of hypoglycemic shock (2). Therefore, nowadays, due to public awareness on the problems and complications of diabetes, the need to find the effective compounds with no side effects in the treatment of this disease is greatly felt. In this regard, many researchers in their studies have focused on medicinal plants effective on this disease (3). The use of herbal medicines can be considered as an alternative treatment due to the reason that herbal medicines show less toxicity, less harm, and fewer side effects (4). In Turkey and Morocco, Nettle is traditionally used to control blood sugar level in the body. Some previous studies have also shown the effects of this plant on lowering fast blood sugar level. Accordingly, Nettle leaves contain several natural compounds such as flavonoids, peptides, and amines and have antidiabetic effects (5). It was reported that Nettle aqueous extract regenerated pancreatic beta cells through its antioxidant 
properties and scavenging free radicals, thereby lowering the blood sugar level of rats (6). Moreover, some studies have shown that Cumin is one of the plants, the consumption of which has a lowering effect on blood glucose level in diabetics. It has also been shown to reduce the total cholesterol, triglycerides, and serum LDL levels (7). Nanotechnology has been developed due to having the advantages of different applications in various fields (8-10). Currently, the use of plants has expanded for the preparation of nanomaterials (11). Recently, Nano emulsion has attracted much attention for its biological application (9). Of note, Nano emulsion is an important tool used in the field of medicine that is designed for clinical and therapeutic usages (12). Nano emulsion is a colloidal particle system consisting of two heterogeneous liquids like a mixture of water and oil (13). Oil-in-water Nano emulsions mainly contain small droplets of oil less than $100 \mathrm{~nm}$ in diameter dispersed in a continuous aqueous phase, and each oil droplet is also surrounded by thin layers of emulsifier molecules (14). Thus, based on this concept and increasing frequency of diabetes disease, it seems that both the prevention and management of sequels of these diseases such as neuropathy and other metabolic disorders are critical. This study aimed to evaluate the possible effect of treatment with the nettle Nano emulsion, aqueous extract, and Cuminum cyminum L essence on the modulation of diabetes-induced neurotoxicity, neuropathy, hyperglycemia in rats' sciatic nerve as well as investigating potential anti-oxidant, antiapoptotic, and anti-inflammatory effects on sciatic nerve histological changes.

\section{Materials And Methods}

\subsection{General procedure Medicinal chemistry section}

All the chemicals in this study had analytical grade. Ultrapure water was used for the preparation of all the reagents solutions. As well, Tween 80 was purchased from Merck Millipore (Darmstadt, Germany) as a surfactant. Nettle aqueous extract and Cumin essential oil were prepared from Adonis Gol Daro laboratory (Iran) as the aqueous phase, and Barij Essence (Iran) was prepared as the oil phase, respectively.

Nettle aqueous extract was prepared using a simple method. Nettle in Iran was collected from Kashan in July and from Mazandaran in May. The samples were thoroughly washed with double distilled water, in order to remove the dust particles. Thereafter, these were approved by Herbarium PMP-1379 for Nettle (Urtica dioica) Tehran University. Finally, the samples were cut into very fine pieces and then dried in the presence of sunlight. For the preparation of the required extract, $500 \mathrm{~g}$ of the samples was immersed in the $4 \mathrm{~L}$ of DD water and then boiled to prepare $1 \mathrm{~L}$ of the extract. Thereafter, the nanoemulsions were prepared by ultrasonic bath for 18 minutes (Table-1) and the component percentage was estimated according to the previous reports (12). The samples were characterized by DLS for investigating size and size distribution of the particles (ZEN314, England) and TEM was used to observe morphology and size of nanoemulsions (Zeiss-EM10C-100 KV, Germany).

\section{2. General procedure pharmacological section}

\section{2.1. Animals}


In the current study, 100 male rats weighing between 20 and $250 \mathrm{~g}$, were purchased from the lab house of Iran University of Medical Sciences. They were kept under the controlled conditions, at room temperature $\left(22 \pm 0.5^{\circ} \mathrm{C}\right)$ with 12 -h light/dark cycles, and had free access to food and water. These animals were separated into experimental groups.

\subsubsection{Ethics Statement}

Our experimental procedure was approved by the Ethical Committee of the Islamic Azad University, Tehran central branch, Tehran, Iran and this research was performed in terms of the Guidelines of Animal Ethics and Welfare and the guideline of Islamic Azad University in agreement with ARRIVE (Animal Research: Reporting of In Vivo Experiments) procedures (15). This paper was prepared from the data obtained from the master of sciences thesis and ethical code of these two research projects was IR.IAU.PS.REC.1397.100.

\subsubsection{Drug}

Streptozocin (STZ) and metformin were obtained from Sigma-Aldrich (USA) and then dissolved freshly in normal saline prior to administration.

\subsubsection{Experimental procedures for the evaluation of neuroprotective and hypoglycemic effects of the nanoemulsion and nettle aqueous extract}

\section{In this regard, 100 rats were randomly divided into 9 groups as follows:}

- Group 1 (control group) was administrated with $0.2 \mathrm{ml} /$ rat, i.p, normal saline, as a vehicle, for a seven-week period.

- Group 2 was given a single dose of Streptozocin (65 mg/kg, i.p) and did not receive any special treatment for five consecutive weeks.

- Groups 3, 4, and 5 concurrently received a single dose of Streptozocin (65 mg/kg, i.p) and after 14 days, they received nettle (Urtica dioica) aqueous extract (50, 100, and $200 \mathrm{mg} / \mathrm{kg}$, i.p., respectively) for five consecutive weeks.

- Groups 6, 7, and 8 concurrently received a single dose of Streptozocin (65 mg/kg, i.p) and after 14 days, they received the Nano emulsion $(25,50$, and $100 \mathrm{mg} / \mathrm{kg}$, i.p., respectively) for five consecutive weeks.

- Group 9 concurrently received a single dose of Streptozocin (65 mg/kg, i.p) and after 14 days, it received metformin (150 mg/kg, i.p.) that was dissolved in normal saline for five consecutive weeks.

- Group 10 concurrently received a single dose of Streptozocin (65 mg/kg, i.p) and after 14 days, it received Cuminum cyminum $L$ essence $(4 \mathrm{mg} / \mathrm{kg}$, i.p.) for five consecutive weeks. Afterward, this group was added to the experiment because the Cuminum cyminum $L$ essence was used in the oil phase of the nanoemulsion preparation. 
It should be mentioned that in the groups 3 to 9 , the animal firstly became diabetic with STZ, and after confirming their diabetic state, on day 14 , their treatment process continued for 5 consecutive weeks. After the treatment, serum levels of glucose; insulin; and pro-inflammatory cytokines, including tumor necrosis factor (TNF)-a, interleukin (IL)-1ß, and IL-6, were determined. Furthermore, the sciatic tissue levels of thiobarbituric acid, the reduced glutathione (GSH), oxidized glutathione (GSSG) were determined, as well as the activity levels of superoxide dismutase, catalase, glutathione peroxidase, and glutathione reductase. Moreover, insulin-like growth factor (IGF), nerve growth factor (NGF), TNF-a, IL-1ß, IL-6 Bax, Bcl2 , and Caspase-3 levels were assessed in the sciatic tissue. Finally, the sciatic nerve tissue samples were analyzed for histopathological alterations.

\subsubsection{Behavioral tests}

\subsubsection{Mechanical hyperalgesia (using Randall-Selitto method).}

At this stage, the mean right and left paw pressure thresholds were determined using an MK-20D paw pressure analgesia meter (Muromachi Kikai Co. Ltd., Tokyo, Japan). For this purpose, the pressure linear increase rate was fixed at $10 \mathrm{mmHg} / \mathrm{sec}$ and the cut-off pressure was also set at $500 \mathrm{mmHg}$ to avoid tissue injury. The pressure was then applied to the center of the hind paw. When the rats had pain by the withdrawal of the paw, the applied paw pressure was recorded using the analgesia meter and then expressed in $\mathrm{mmHg}$. Three tests were performed for each rat, each one with at least 10 min interval, and the mean value was finally recorded $(16,17)$.

\subsubsection{Tail flick test.}

Acute nociception was induced using a Socrel model DS 20 tail-flick apparatus (Apelex, Bagneux, France). In brief, by focusing an intensity-controlled beam of light on the distal $2 \mathrm{~cm}$ of the rats' tail, the tail-flick latency of the restrained ones was measured. Next, the period required for the rats to remove their tail from this thermal stimulus was recorded. To avoid any manual error, two or three recordings were measured at an interval of $15 \mathrm{~min}$ for each rat, and the mean value was also calculated for the statistical analyses $(18,19)$.

\section{3: Molecular and biochemical measurements 2.3.1. Serum Insulin and glucose levels}

Serum levels of glucose and insulin were determined in this phase using commercially available diagnostic kits (Randox Laboratories Ltd., Crumlin, County Antrim, UK) $(20,21)$.

\subsubsection{Total protein extraction and the determination of protein concentration}

The study animals were anesthetized using thiopental sodium (50 mg/kg, i.p) and the hippocampus was then separated from each rat. Thereafter, the isolated tissues were separately homogenized in the cold 
homogenization buffer (25mM 4-morpholinepropanesulfonic acid, $400 \mathrm{mM}$ sucrose, $4 \mathrm{mM}$ magnesium oxide (MgCl2), $0.05 \mathrm{mM}$ ethylene glycol tetraacetic acid (EGTA), and pH 7.3) and these homogenized tissues were centrifuged at $450 \mathrm{~g}$ for $10 \mathrm{~min}$. The acquired supernatants were re-centrifuged at $12000 \mathrm{~g}$ for $10 \mathrm{~min}$. Finally, the sediments were re-suspended in the homogenization buffer and then stored at $0^{\circ} \mathrm{C}$. A Dc protein assay kit (Bio-Rad) (California, USA) was used to determine the total protein of the homogenized tissues. Next, this protein extraction was used for the evaluation of the level, activity, and/or concentration of some proteins such as BDNF, CREB (total and phosphorylated), TNF-a, IL-1 $\beta, B a x$, and $\mathrm{Bcl}-2$, SOD, GPx, and GR in terms of the following protocols. As well, for determining the total protein concentration, the Bradford technique was used. To fulfil this, briefly; Bradford reagent (1 part Bradford: 4 parts $\mathrm{dH} 2 \mathrm{O}$ ) was added to the serial dilution sequence $(0.1-1.0 \mathrm{mg} / \mathrm{ml})$ of a specified protein sample concentration; e.g., bovine serum albumin (BSA), which was previously dissolved in homogenization buffer. These serial dilution series were prepared and then used to provide a standard curve. On the other hand, $10,15,20,25$, and $30 \mu$ of the protein extracts (homogenized cell solutions) were added to various wells. Additionally, the Bradford reagent was added to the wells. Thereafter, the plate reader read the color density of all the wells at $630 \mathrm{~nm}$. Finally, the amount of each protein in the extracts was acquired using the standard curve. All the measured proteins were reported based on the total protein concentration in the homogenized cell solutions, which were measured using the Bradford method (22-25).

\subsubsection{Measurement of the oxidative stress parameters 2.3.2.1. Determination of lipid peroxidation}

At this stage, Malondialdehyde (MDA), which is a natural by-product, was evaluated for lipid peroxidation. Briefly, $100 \mu$ of SDS lysis solution was added to the wells comprising of the sample solution $(100 \mu \mathrm{l})$ or MDA standard. After shaking and incubating these wells, $250 \mu \mathrm{l}$ of thiobarbituric acid (TBA) reagent was added to each well and then incubated for $45-60 \mathrm{~min}$ at $95^{\circ} \mathrm{C}$. Next, the tubes were centrifuged at $1000 \mathrm{~g}$ for $15 \mathrm{~min}$ and $300 \mu \mathrm{l}$ of $\mathrm{n}$-butanol was then added to $300 \mu \mathrm{L}$ of the supernatants. Thereafter, the tubes were centrifuged at $10,000 \mathrm{~g}$ for 5 minutes. Finally, the absorbance rate was read at $532 \mathrm{~nm}$ and the findings were expressed as nmol/mg of protein (22-27).

\subsubsection{Determination of GSH (Glutathione) and GSSG (Glutathione disulfide) contents}

To measure the concentrations of both GSH (glutathione) and GSSG (glutathione disulfide), $25 \mu$ of the $1 \mathrm{X}$ glutathione reductase solution and $25 \mu \mathrm{l}$ of the 1X NADPH solution were added either to a 96-well tray comprising of a normal glutathione solution or to a sample consisting of the homogenized solution. Subsequently, $50 \mu \mathrm{l}$ of the $1 \mathrm{X}$ Chromogen was added to each well and blended strenuously. Finally, for each GSSG / GSH standard and sample, the absorbance rate was read at $405 \mathrm{~nm}$. Finally, using the standard curve, GSSG / GSH concentrations were quantified and then expressed as $\mathrm{nmol} / \mathrm{mg}$ of protein $(27,28)$. 


\subsubsection{Determination of manganese superoxide dismutase (MnSOD) activity}

The technique outlined earlier was used to evaluate the SOD activity (27-29). The following equation was also used to measure the SOD activity: (27-29).

\subsubsection{Determination of glutathione peroxidase (GPx) activity}

In this phase, GPx activity was evaluated as described earlier (27-29). Accordingly, it was evaluated using the following equation based on a shift in absorption $[\triangle \mathrm{A} 340 / \mathrm{min}]: \Delta \mathrm{A} 340 / \mathrm{min}=\mathrm{A} 340 \mathrm{~nm}$ (Start) A340nm (Stop)/ Reaction time ( $\mathrm{min}$ ), any shift in the absorption was directly proportional to GPx activity. GPx activity: $\triangle \mathrm{A} 340 / \mathrm{min} \times$ Reaction volume $(\mathrm{ml}) \times$ Dilution factor of the original sample / Extinction coefficient for NADPH at $340 \mathrm{~nm} \times$ Volumes of the tested sample. The obtained results were expressed as $\mathrm{mU} / \mathrm{mg}$ protein (27-29).

\subsubsection{Determination of glutathione reductase (GR) activity}

GR activity was evaluated as described earlier (27-29). Accordingly, it was measured based on a change in the absorbance rate $[\triangle \mathrm{A} 340 / \mathrm{min}]$ using the following equation:

$\Delta \mathrm{A} 340 / \mathrm{min}=\mathrm{A} 340 \mathrm{~nm}$ (Start) $-\mathrm{A} 340 \mathrm{~nm}(\mathrm{Stop}) /$ Reaction time (min), any change in the absorbance was directly proportional to GR activity.

GR activity: $\triangle A 340 / \mathrm{min} \times$ Reaction volume $(\mathrm{ml}) \times$ Dilution factor of the original sample / Extinction coefficient for NADPH at $340 \mathrm{~nm} \times$ Volumes of the tested sample. The obtained results were expressed as $\mathrm{mU} / \mathrm{mg}$ protein (27-29).

\subsubsection{Determination of glutathione peroxidase catalase (CAT) activity}

At this stage, GR activity was evaluated as described previously (30). The results were expressed as $\mathrm{mU} / \mathrm{mg}$ protein (30).

\subsubsection{Determination of protein expression alteration}

Concentrations (protein expressions) of TNF- $a$, IL-1 $\beta$, IL-6, Bax, Bcl-2, Caspase-3, Caspase-7, NGF, and IGF in sciatic nerve tissue cell lysates or blood serums were evaluated using a commercially accessible ELISA kit. In the present research, we selected the ELISA technique for evaluating the protein modifications level. In terms of the guidelines of the ELISA kits, the sensitivity and specificity of the TNF- $a, I L-1 \beta, I L-6, B a x, B c l-$ 2, Caspase-3, Caspase-7, NGF, and IGF kits were estimated to be less than $5 \mathrm{ng} / \mathrm{ml}$ and $76 \%$, respectively. Firstly, for testing the validity of the used methods and in terms of the instructions of the manufacturer of commercial kits for each one of the above-mentioned proteins, a standard curve was produced by plotting the average blank control subtracted absorbance value for each standard concentration (in the $y$ - 
axis) against the target protein concentration (x-axis) of the standard one. Thereafter, we used a software to draw the best fit (least squares) through these points, in order to construct the standard curve. Next, using ELISA protocol, as below, we obtained their optical density (OD) by ELISA reader for each sample. Accordingly, this OD was then inserted in the constructed standard curve and the concentration of the protein was obtained at last. Of note, the following protocol was used For ELISA: Briefly, the wells containing sheep anti-rat TNF-a, IL-1 $\beta$, IL-6, Bax, Bcl-2, Caspase-3, Caspase-7, NGF and IGF polyclonal antibodies (Sigma Chemical Co., Poole, and Dorset, UK) were washed three times with washing water (0.5 $\mathrm{M}$ of sodium chloride $(\mathrm{NaCl}), 2.5 \mathrm{mM}$ of sodium dihydrogen phosphate (NaH2PO4), $7.5 \mathrm{mM} \mathrm{Na} 2 \mathrm{HPO} 4$, $0.1 \%$ Tween 20, and pH 7.2). Thereafter, $100 \mathrm{ml}$ of 1 percent (w/v) ovalbumin (Sigma Chemical Co., Poole, Dorset, UK) solution was added to each well and incubated for $1 \mathrm{~h}$ at $37^{\circ} \mathrm{C}$. After three times washing, $100 \mathrm{ml}$ of both the samples and standards were added to each well and incubated for $20 \mathrm{~h}$ at $48^{\circ} \mathrm{C}$. After washing for three times, $100 \mathrm{ml}$ of the biotinylated sheep anti-rat IL-1 $\beta$, IL-6, and TNF- $\mathrm{a}$ antibody (1:1000 dilutions in washing buffer comprising 1 percent sheep serum, Sigma Chemical Co., Poole, and Dorset, UK) were added to each study well. Next, after 1-hour incubation and three times washing, $100 \mathrm{ml}$ of avidin-HRP (Dako Ltd, UK) (1:5000 wash buffer dilution) was added to each well and the plate was then incubated for 15 minutes. After washing for three times, $100 \mathrm{ml}$ of TMB substrate solution (Dako Ltd., UK) was added to each well and then incubated for 10 minutes at room temperature. Subsequently, $100 \mathrm{ml}$ of $1 \mathrm{M} \mathrm{H}_{2} \mathrm{SO}_{4}$ was added and the absorbance rate was read at $450 \mathrm{~nm}$. The obtained results were expressed either as ng/mg IL-1 13 , as TNF-a, IL- 6 or as Bax and Bcl-2, Caspase- 3 and Caspase-7, and pg/mg of NGF and IGF. Additionally, the serum level of IL-1 $\beta$, TNF- $\alpha$, or IL- 6 was reported as $\mathrm{ng} / \mathrm{ml}$. It should be noted that the above-mentioned proteins as $\mathrm{ng} / \mathrm{mg}$ or $\mathrm{pg} / \mathrm{mg}$ were reported in terms of the instructions of the manufacturer of each ELISA kit, finally, their standard curve was plotted as $\mathrm{ng} / \mathrm{ml}$ or $\mathrm{pg} / \mathrm{ml}(31-33)$.

\subsection{Statistical analysis}

The data were analyzed using GraphPad PRISM v.6 software (2016) (Graph Pad Company, San Diego, USA). Firstly, the normality of the continuous variables (both behavioral and molecular parameters) was assessed using the Kolmogorov-Smirnov test. Based on the result of this test, all variables were found to be normally distributed. All these data were described as means \pm standard error of the mean. The difference between the treatment groups was evaluated using one-way ANOVA with Bonferroni's posthoc-test for performing group-by-group comparisons. The results were considered as statistically significant at both the $P<0.05$ and $P<0.001$ levels.

\section{Results}

\subsection{Results of the medicinal chemistry section}

\subsubsection{DLS}


The size and size distribution of nanoemulsion were evaluated by dynamic light scattering. DLS results showed a single-peak with a narrow distribution and different sizes (Figure-1). Based on the obtained results, the optimum percentage was observed for the nanoemulsion, including Cumin essential oil ( $4 \%$ $\mathrm{w} / \mathrm{w})$, nettle aqueous extract $(95 \% \mathrm{w} / \mathrm{w})$, and Tween 80 surfactant $(1 \% \mathrm{w} / \mathrm{w})$.

\subsubsection{Transmission electron microscopy}

TEM image of the Nano emulsion is presented in Fig. 2. Based on the results, the nanoparticles had spherical shape and smooth surface with narrow size distribution as about $34.5 \mathrm{~nm}$.

\subsection{Results of the Pharmacological section}

3.2.1. Effects of nettle (Urtica dioica) aqueous extract and the nanoemulsion nettle on the mechanical and thermal pain thresholds

As shown in Figs. $3 A$ and $B$, diabetic rats indicated a significant reduction in the paw pressure analgesia and tail flic test when compared to the control group $(P<0.001)$. While the administration of nettle (Urtica dioica) aqueous extract (50, 100, and $200 \mathrm{mg} / \mathrm{kg}$, i.p.) as well as the nanoemulsion (25, 50, and 100 $\mathrm{mg} / \mathrm{kg}$, i.p.) for five consecutive days significantly increased the withdrawal time in paw pressure analgesia and tail flic test latency time in the studied diabetic rats $(P<0.001)$ ( Figs. $3 A$ and $B)$. In addition, the administration pf metformin $(150 \mathrm{mg} / \mathrm{kg}$, i.p.) for five consecutive days significantly increased the withdrawal time in paw pressure analgesia and tail flic test latency time in the studied diabetic rats $(P<0.001)$ (Figs. $3 A$ and $B)$. as well, the use of Cuminum cyminum $L$ essence $(4 \mathrm{mg} / \mathrm{kg}$, i.p.) significantly increased the withdrawal time in paw pressure analgesia and tail flic test latency time in the studied diabetic rats $(P<0.001)$ ( Figs. $3 A$ and $B)$.

3.2.2. Effects of nettle (Urtica dioica) aqueous extract and the nanoemulsion nettle on blood insulin and glucose levels

The diabetic rats indicated a significant reduction in insulin level and an increase in glucose level when compared to the control group $(\mathrm{P}<0.001)$ (Figs. $4 \mathrm{~A}$ and $\mathrm{B}$ ). In contrast, the administration of nettle (Urtica dioica) aqueous extract (50, 100, and $200 \mathrm{mg} / \mathrm{kg}$, i.p.) as well as the nanoemulsion $(25,50$, and 100 $\mathrm{mg} / \mathrm{kg}$, i.p.) for five consecutive days in the diabetic rats caused a significant increase in insulin level and a decrease in glucose level $(P<0.001)$ (Figs. $4 \mathrm{~A}$ and $\mathrm{B})$. Moreover, the administration of metformin (150 $\mathrm{mg} / \mathrm{kg}$, i.p.) for five consecutive days significantly increased insulin level and decreased glucose level in the studied diabetic rats $(P<0.001)$ (Figs. $2 A$ and $B)$. Finally, the use of Cuminum cyminum $L$ essence (4 $\mathrm{mg} / \mathrm{kg}$, i.p.) significantly increased insulin level and decreased glucose level in the diabetic rats $(P<$ 0.001)(Figs. 4A and B).

3.2.3. Effects of nettle (Urtica dioica) aqueous extract and the nanoemulsion nettle on the blood levels of TNF-a, IL-1ß, and IL-6

At this stage, the diabetic rats indicated a significant reduction in the blood levels of TNF-a, IL-1ß, and IL- 6 when compared to the control group $(P<0.001)$ (Figs. 5A, B, and C). However, the administration of both 
nettle (Urtica dioica) aqueous extract (50, 100, and $200 \mathrm{mg} / \mathrm{kg}$, i.p.) and the nanoemulsion (25, 50, and $100 \mathrm{mg} / \mathrm{kg}$, i.p.) for five consecutive days in the diabetic rats caused remarkable reduction in the blood levels of TNF-a, IL-1B, and IL-6 ( $P<0.001$ ) (Figs. 5A, B, and C). Furthermore, the use of Metformin (150 $\mathrm{mg} / \mathrm{kg}$, i.p.) for five consecutive days significantly decreased blood levels of TNF-a, IL-1ß, and IL-6 in the diabetic rats $(P<0.001)$ (Figs. $5 A, B$, and $C$ ). Finally, the administration of Cuminum cyminum $L$ essence (4 mg/kg, i.p.) significantly decreased blood levels of TNF-a, IL-1ß, and IL-6 in the diabetic rats $(P<0.001)$ (Figs. 5A, B, and C).

\subsubsection{Effects of nettle (Urtica dioica) aqueous extract and the nanoemulsion nettle on sciatic GSH and GSSG levels}

The diabetic rats indicated a significant increase in GSSG level and a decrease in GSH level when compared to the control group $(\mathrm{P}<0.001)$ (Table-2). However, the administration of nettle (Urtica dioica) aqueous extract (50, 100, and $200 \mathrm{mg} / \mathrm{kg}$, i.p.) and the nanoemulsion $(25,50$, and $100 \mathrm{mg} / \mathrm{kg}$, i.p.) for five consecutive days in the diabetic rats indicated a significant increase in GSH level and a decrease in GSSG level $(P<0.001)$ (Table-2). Additionally, the use of metformin $(150 \mathrm{mg} / \mathrm{kg}$, i.p.) for five consecutive days significantly decreased the GSSG level and also increased the GSH level in the diabetic rats $(P<0.001)$ (Table-1). Of note, by administrating Cuminum cyminum L essence (4 mg/kg, i.p.), GSSG significantly decreased and GSH increased in the diabetic rats $(P<0.001)($ Table-2).

\subsubsection{Effects of nettle (Urtica dioica) aqueous extract and the nanoemulsion nettle on sciatic level of MDA and antioxidant enzymes}

The studied diabetic rats indicated a significant increase in MDA level and decrease in SOD, GPx, GR, and CAT levels when compared to the control group $(P<0.001)$ (Figs. 6A, B, C, D, and E). However, the administration of both nettle (Urtica dioica) aqueous extract (50, 100, and $200 \mathrm{mg} / \mathrm{kg}$, i.p.) and the nanoemulsion $(25,50$, and $100 \mathrm{mg} / \mathrm{kg}$, i.p.) for five consecutive days in the diabetic rats indicated significant increases in SOD, GPx, GR, and CAT levels and a decrease in MDA level $(P<0.001)$ (Figs. 6A, B, $C, D$, and $E)$. In addition, the use of metformin $(150 \mathrm{mg} / \mathrm{kg}$, i.p.) for five consecutive days significantly decreased MDA level and increased SOD, GPx, GR, CAT levels in the diabetic rats $(P<0.001)$ (Figs. 6A, B, $\mathrm{C}, \mathrm{D}$, and $\mathrm{E})$. As well, the use of Cuminum cyminum $L$ essence $(4 \mathrm{mg} / \mathrm{kg}$, i.p.) significantly decreased MDA and increased SOD, GPx, GR, CAT levels in the diabetic rats $(P<0.001)$ (Figs. 6A, B, C, D, and E).

3.2.6. Effects of nettle (Urtica dioica) aqueous extract and the nanoemulsion nettle on sciatic levels of TNF-a, IL-1ß, and IL-6

The diabetic rats indicated a significant reduction in the levels of TNF-a, IL-1ß, and IL- 6 when compared to the control group $(\mathrm{P}<0.001)$ (Figs. 7A, B, and C). However, the administration of nettle (Urtica dioica) aqueous extract (50, 100, and $200 \mathrm{mg} / \mathrm{kg}$, i.p.) and the nanoemulsion (25, 50, and $100 \mathrm{mg} / \mathrm{kg}$, i.p.) for five consecutive days cause remarkable reduction in the levels of TNF-a, IL-1ß, and IL- 6 in the diabetic rats ( $P$ $<0.001$ ) (Figs. 7A, B, and C). As well, the use of Metformin (150 mg/kg, i.p.) for five consecutive days significantly decreased the levels of TNF-a, IL-1B, and IL-6 in the diabetic rats $(P<0.001)$ (Figs. 7A, B, and 
C). Of note, Cuminum cyminum $L$ essence ( $4 \mathrm{mg} / \mathrm{kg}$, i.p.) significantly decreased the sciatic levels of TNFa, IL-1ß, and IL- 6 in these diabetic rats $(P<0.001)$ (Figs. 7A, B, and C).

3.2.7. Effects of nettle (Urtica dioica) aqueous extract and the nanoemulsion nettle on sciatic levels of Bax, caspase-3, caspase-7, and Bcl-2

The diabetic rats indicated a significant reduction in Bcl-2 level and an increase in Bax, caspase-3, and caspase-7 levels when compared to the control group $(\mathrm{P}<0.001)$ (Figs. $8 \mathrm{~A}$ and $\mathrm{B}$ ). The administration of nettle (Urtica dioica) aqueous extract $(50,100$, and $200 \mathrm{mg} / \mathrm{kg}$, i.p.) and the nanoemulsion $(25,50$, and $100 \mathrm{mg} / \mathrm{kg}$, i.p.) for five consecutive days in the diabetic rats indicated a significant increase in Bcl-2 level and decreases in Bax, caspase-3, and caspase-7 levels $(P<0.001)$ (Figs. 8A and B). Furthermore, the use of metformin (150 mg/kg, i.p.) for five consecutive days significantly increased Bcl-2 level and decreased Bax, caspase-3, and caspase-7 levels in the diabetic rats $(P<0.001)$ (Figs. 8A and B). Additionally, Cuminum cyminum $L$ essence ( $4 \mathrm{mg} / \mathrm{kg}$, i.p.) significantly decreased Bax, caspase-3, and caspase-7 levels, and increased $\mathrm{Bcl}-2$ in the diabetic rats $(\mathrm{P}<0.001)$ (Figs. $8 \mathrm{~A}$ and $\mathrm{B})$.

3.2.8. Effects of nettle (Urtica dioica) aqueous extract and the nanoemulsion nettle on sciatic levels of NGF and IGF

The diabetic rats indicated significant reduction in both NGF and IGF levels when compared to the control group $(\mathrm{P}<0.001)$ (Figs. 9A and $\mathrm{B})$. The administration of nettle (Urtica dioica) aqueous extract $(50,100$, and $200 \mathrm{mg} / \mathrm{kg}$, i.p.) and nanoemulsion (25,50, and $100 \mathrm{mg} / \mathrm{kg}$, i.p.) for five consecutive days in these diabetic rats also indicated significant increase in NGF and IGF levels $(P<0.001)$ (Figs. 9A and B). The use of Metformin (150 mg/kg, i.p.) for five consecutive days significantly increased NGF and IGF levels in the diabetic rats $(P<0.001)$ (Figs. $9 A$ and $B)$. It is noteworthy that Cuminum cyminum $L$ essence $(4$ $\mathrm{mg} / \mathrm{kg}$, i.p.) significantly increased NGF and IGF levels in the diabetic rats $(P<0.001)$ (Figs. 9A and $B)$.

3.2.9. Effects of nettle (Urtica dioica) aqueous extract and the nanoemulsion nettle on the sciatic histological changes

The studied animals indicated significant necrosis, vacuolation, and edema of cells in sciatic tissue as well as the spaces' cell layer. As well, the decreased cell density was observed when compared to the controls (Figure-10). Conversely, the administration of nettle (Urtica dioica) aqueous extract (50, 100, and $200 \mathrm{mg} / \mathrm{kg}$, i.p.) and the nanoemulsion (25,50, and $100 \mathrm{mg} / \mathrm{kg}$, i.p.) for five consecutive days in the diabetic rats indicated the inhibited STZ-induced necrosis, vacuolation, and edema of a sciatic nerve cell and also caused the reduction of spaces in cell layer of sciatic. Moreover, it caused the increased cell density when compared to the STZ alone treated group (Figure-10). Also, the use of metformin (150 $\mathrm{mg} / \mathrm{kg}$, i.p.) and Cuminum cyminum $L$ essence ( $4 \mathrm{mg} / \mathrm{kg}$, i.p.) for five consecutive days significantly inhibited STZ induced necrosis, vacuolation, and edema of a sciatic nerve cell and caused the reduced spaces in cell layer of sciatic. This also caused the increased cell density when compared to the STZ alone treated group (Figure-10).

\section{Discussion}


The results of the present study indicate that nettle (Urtica dioica) aqueous extract (50, 100, and 200 $\mathrm{mg} / \mathrm{kg}$, i.p.) and the Nano emulsion (25, 50, and $100 \mathrm{mg} / \mathrm{kg}$, i.p.) exert ameliorative effects on STZ induced diabetes and neuropathy. Our data also indicated that nettle aqueous and the Nano emulsion could ameliorate diabetes-induced molecular, biochemical, and histopathological alterations in the sciatic nerves of the studied rats. According to the results of our study, nettle aqueous and the Nano emulsion can inhibit the occurrences of oxidative stress, inflammation, apoptosis, and cell death in the sciatic nerve of the diabetes rat. Thus, it was suggested that nettle aqueous and the Nano emulsion can inhibit STZinduced hyperglycemia and reduce injury of the peripheral nervous system by modulating oxidative stress, inflammation, apoptosis, and cell death in the sciatic nerve, and as a neuroprotective agent, these can also inhibit diabetes-induced neuropathy.

Diabetes mellitus (DM), commonly called diabetes, is a group of metabolic disorders characterized by a high blood sugar level through a prolonged period of time (34). Accordingly, this metabolic disease has several complications and sequels, the treatment and management of which are included as the most important and key issues that should be considered (34). Diabetic neuropathy is one of the serious diabetes complications that may affect as many as $50 \%$ of people with diabetes $(34,35)$. Moreover, diabetic neuropathy is a type of nerve damage that can occur in patients with diabetes. A high blood sugar level (glucose) can injure nerves in all parts of the body. Diabetic neuropathy most often damages nerves in legs and feet, especially sciatic nerve that has high involvement after diabetes neuropathy (35, 36).

In recent years, many previous studies demonstrated that nanotechnology can improve some effects of synthetic and herbal-based antidiabetic agents and consequently cause the enhanced heir pharmacokinetics and pharmacodynamics properties. Therefore, it is expected that nanotechnology can enhance all the desirable properties of antidiabetic agents compared to when they are used alone (37). Nanotechnology (or "nanotech") is the manipulation of matter on atomic, molecular, and supramolecular scales (38-40). As well, it can create many new effects, materials, and a vast range of applications for curcumin $(38,41)$. Drug delivery is one of the most important topics in which Nanomedicines technology can help in the improvement of drug effects providing the possibility of delivering all therapeutic agents to some specific cells and tissues such as the neuron using nanoparticles (38-40). Additionally, on the other way, by the use of nanomedicine technology for the enhancement of the therapeutic efficacy, the overall uses and consumption of this agent would be reduced and the side-effects may be significantly lowered by depositing the active agents in the morbid region only and in no higher dose than needed (40). The targeted drug delivery is intended to reduce its side effects with concomitant decreases in the consumption and treatment expenses (38-40). According to the concept of nanotechnology benefit, in this study, we attempted to evaluate the Nano emulsion and nettle (Urtica dioica) aqueous extracts' effects on the inhibition of STZ-induced diabetes and neuropathy. In this manner, we evaluated their molecular, biochemical, and histological effects and then tried to compare the effects of the Nano emulsion with those of nettle (Urtica dioica) aqueous extract. The results of the current study indicate that STZ causes a reduction in the paw pressure analgesia and tail flic test when compared to the control group. Accordingly, this is consistent with the findings of the previous studies demonstrating that 
diabetes causes ending nerve damages and by this mechanism, it increases their sensitization to pain stimulation (42). Hyperalgesia is one of the main complications of diabetes, which is resulted from damage to nociceptors or peripheral nerves $(43,44)$. In contrast, in the present study, the administration of nettle (Urtica dioica) aqueous extract (50, 100, and $200 \mathrm{mg} / \mathrm{kg}$, i.p.) and the Nano emulsion $(25,50$, and $100 \mathrm{mg} / \mathrm{kg}$, i.p.) for five consecutive days significantly increased the withdrawal time in paw pressure analgesia and tail flic test latency time in the diabetic rats. Correspondingly, this result is somehow consistent with those of previous studies on the role of Urtica dioica (nettle) on the management of diabetes complications (45). Urtica dioica is a therapeutic herbal compound, which is used as an antihypertensive, anti-hyperlipidemia, and antidiabetic herbal medicine (45-47). Accordingly, in Iran's folk medicine, Urtica dioica is known to have hypotensive and antidiabetic activities (48). This agent reduces blood glucose level by oral ingestion. Moreover, it was shown that a preparation containing various plants with Urtica dioica extract would have an antidiabetic activity (49). However, Urtica dioica extract or even its Nano emulsion effects on diabetes-induced neuropathy are not clarified yet, so the result of the present study can be considered as unique in this regard. According to the current study, the use of metformin (150 mg/kg, i.p.) significantly increased the withdrawal time in paw pressure analgesia and tail flic test latency time in the diabetic rats, confirming its protective effect on diabetes neuropathy. Furthermore, previous studies demonstrated the neuroprotective role of metformin (50-52). As mentioned earlier regarding the preparation of Nano emulsion of nettle, we used Cuminum cyminum $L$ essence in the oil phase, and as a result, our study indicated that Cuminum cyminum $L$ essence $(4 \mathrm{mg} / \mathrm{kg}$, i.p.) significantly increased the withdrawal time in paw pressure analgesia and tail flic test latency time in the diabetic rats. The roles of Cuminum cyminum $L$ essence in the management of diabetes and its related complications in human d experimental subject were approved previously $(53,54)$. Based on the results of the current study, it can be interpreted that some parts of the Nano emulsion of nettle beneficial effects on the management of diabetes hyperalgesia are mediated by Cuminum cyminum $L$ essence, which is used inside this Nano emulsion.

The results of the current study indicate that STZ causes an increase in blood glucose levels and a reduction in insulin levels when compared to the control group. Accordingly, this is consistent with previous studies, demonstrating that the STZ-induced diabetes in the rodent is known as the standard model of diabetes induction (51). In contrast, in the present study, the administration of nettle (Urtica dioica) aqueous extract and the Nano emulsion significantly decreased blood glucose level and increased insulin level. Of note, Urtica dioica is an anti-hyperglycemic therapeutic herbal compound used as extract and crude extract (55). But the Nano emulsion effects on hyperglycemia and insulin deficiency are not clarified yet. The result of the present study can be exclusive because the Nano emulsion form of nettle requires lower doses to become more effective than the crude extract and this may be due to the role of nanotechnology, since it will increase the effects of the drug at a lower dose and the same time reduce its side effects (56). According to the current study, metformin and Cuminum cyminum $L$ essence could significantly decrease blood glucose level and increase insulin level, confirming the previous studies' results regarding the anti-hyperglycemic effects of metformin $(52,54,57)$. Besides, it seems that some 
parts of the Nano emulsion of nettle beneficial effects on managing blood glucose and insulin levels can be mediated by the Cuminum cyminum $L$ essence, which is used inside in the Nano emulsion.

According to the current study, blood level and the sciatic level of inflammatory parameters such as TNFa, IL- $1 B$, and IL- 6 , are higher when compared to the control group. Correspondingly, this is consistent with the findings of previous studies, demonstrating that diabetes is an inflammatory disease and inflammation plays a critical role in the pathophysiology of this disease $(58,59)$. Moreover, Diabetes is more considered as an immunological response rather than a metabolic disorder and the preliminary results of trials using anti-inflammatory and immunomodulatory medication are promising in this regard (58-60). Besides, it can be known as an enterprise that activates these inflammatory parameters in both blood and sciatic and is responsible for the occurrence of sciatic nerve neuropathy (58-60). In contrast, in the present study, the administration of nettle (Urtica dioica) aqueous extract and the Nano emulsion significantly decreased blood and sciatic levels of TNF-a, IL-1ß, and IL-6. In this regard, a previous study demonstrated the anti-inflammatory role of Urtica dioica in multiple diseases; however, its exact roles in the modulation of inflammatory during diabetes and in the mediation of inflammation in the STZ-induced diabetes neuropathy are not clarified yet (61-63). Additionally, according to the current data, Nano emulsion form of nettle requires lower doses for being anti-inflammatory when compared to crude extract of nettle and these anti-inflammatory properties are reported for the first time. Correspondingly, due to the role nanotechnology in the potentiation of therapeutic agent, this efficacy of Nano emulsion form of nettle can be justified in lower levels. It seems that Urtica dioica, in both aqueous extract and Nano emulsion form can be effective on the diabetes-induced neuropathy by the modulation of inflammation. According to the current study, both metformin and Cuminum cyminum $L$ essence could significantly decrease blood and sciatic levels of TNF-a, IL-1ß, and IL-6, confirming the previous studies' results regarding the anti-inflammatory effects of metformin and Cuminum cyminum $L$ essence $(64,65)$. Additionally, it seems that some parts of the Nano emulsion of nettle beneficial effects on the management of blood and sciatic levels of inflammatory parameters can be mediated by the Cuminum cyminum $L$ essence, which is used inside in the Nano emulsion.

The current study indicated that the sciatic level of oxidative stress parameters such as MDA and GSSG increased in diabetic rats and some antioxidant parameters such as SOD, GPx, GR, CAT, and GSH decreased when compared to the control group. Correspondingly, this is inconsistent with the previous studies, demonstrating that oxidative stress level increased in diabetic subjects organs, especially neuron (66-68). A previous study also demonstrated that some parts of the diabetes-induced complications were mediated by oxidative stress $(66,67)$. In this regard, the oxidative stress-induced complications of diabetes may include stroke, neuropathy, retinopathy, and nephropathy (69). In many studies, Oxidative stress has been demonstrated to participate in the progression of diabetes, which plays an important role in diabetes, including impairment of insulin action and the increased complication incidence rate (6669). Antioxidants have been already shown to be prospective in the treatment of both diabetes type 1 and type $2(70,71)$. Thus, oxidative stress seems to be more worrying about metabolic disorders, especially diabetes (70). Also, it can be considered as an enterprise that the activation of these oxidative stress parameters in the sciatic nerve is responsible for the occurrence of sciatic nerve neuropathy (72). In 
contrast, in the present study, the administration of nettle (Urtica dioica) aqueous extract and the Nano emulsion significantly decreased the sciatic levels of MDA and GSSG and increased the antioxidant parameters levels such as SOD, GPx, GR, CAT, and GSH. Moreover, a previous study demonstrated the anti-oxidant role of Urtica dioica in multiple diseases, but its exact roles in the modulation of oxidative stress during diabetes and in the mediation of inflammation in the STZ-induced diabetes neuropathy are not clarified yet $(45,73)$. It was demonstrated that some parts of this herbal agent have antioxidant properties in some parts of body organs like liver $(73,74)$. As well, according to the current data, it was indicated that the Nano emulsion form of nettle requires lower doses for being antioxidant when compared to the crude extract of nettle and these anti-oxidant properties are reported for the first time. Accordingly, due to the role nanotechnology in the potentiation of therapeutic agent, this efficacy of Nano emulsion form of nettle can be justified in lower levels. It seems that Urtica dioica, in both aqueous extract and Nano emulsion form, by the modulation of oxidant agent and the activation of antioxidant in the sciatic nerve, can be effective on the diabetes-induced neuropathy and act as an neuroprotective agent $(75,76)$. According to the current study, metformin and Cuminum cyminum $L$ essence could significantly decrease the sciatic levels of MDA and GSSG and increased the levels of the antioxidant parameters such as SOD, GPx, GR, CAT, and GSH. Therefore, these confirm the previous studies' results on the antioxidant effects of metformin and Cuminum cyminum $L$ essence $(64,65,77)$. A previous study indicated that cumin may serve as anti-diabetic treatment and may help in attenuating diabetic complications by improving immune functions and antioxidant situation $(78,79)$. Their results demonstrated that Cuminum cyminum oil played an antioxidant role in reducing oxidative stress in STZsupplemented rats $(78,79)$. Thus, Cuminum cyminum oil may serve as a hypoglycemic natural antioxidant compound and then help in attenuating diabetic complications by reducing oxidative stress and improving immune functions by the modulation of inflammatory parameters $(80,81)$. Also, it seems that some parts of the Nano emulsion of nettle beneficial effects on the management of sciatic level of oxidative stress parameters can be mediated by the Cuminum cyminum $L$ essence, which is used inside the Nano emulsion.

The present study indicated that sciatic level of apoptosis parameters such as Bax, Caspase-3, and Caspase-7 increased in the diabetic rats, while Bcl-2 level decreased. These are also inconsistent with the histopathological results, showing significant necrosis, vacuolation, and edema of cell in sciatic tissue as well as the spaces cell layer. Moreover, these also showed the decreased cell density when compared to the controls. It seems that STZ induced diabetes can cause apoptosis and this leads to the abovementioned quantitative and qualitative histopathological changes in the sciatic nerve. This part of data was confirmed in the previous studies, demonstrating that apoptosis and cell death signaling pathway levels increased in diabetic subjects' organs, especially neuron and this caused histopathological changes of the neural cell of the sciatic nerve, which consequently led to neuropathy $(82,83)$. A previous study demonstrated that some parts of diabetes-induced complication, especially in neuron, were mediated by apoptosis $(83,84)$. Diabetes-induced stroke, neuropathy, retinopathy, and nephropathy have been also resulted from occurrences of apoptosis in the related organs (84). Diabetes-induced cell death signaling was also found to be participating in the progression of impairment of insulin action and the 
increased complication incidence rate (84). Thus, apoptosis and cell death signaling seem to be the most critical matters in metabolic disorders like diabetes (84). It was demonstrated that diabetes-induced apoptosis in the sciatic nerve is responsible for the occurrence of sciatic nerve neuropathy $(85,86)$. In contrast, in the present study, the administration of nettle (Urtica dioica) aqueous extract and the Nano emulsion significantly increased sciatic level of Bax, Caspase-3, and Caspase-7 as well asBcl-2 level. Accordingly, this is inconsistent with the histopathological results, showing that this two types of treatment significantly decreased necrosis, vacuolation, and edema of cell in sciatic tissue as well as spaces of cell layer and cell density in diabetic rats' sciatic nerve. In this regard, a previous study demonstrated the anti-apoptosis role of Urtica dioica in multiple diseases, but its exact roles in the modulation of cell death signaling during diabetes and the mediation of apoptosis in the STZ-induced diabetes neuropathy are not clarified yet $(87,88)$. It was demonstrated that this herbal agent has neuroprotective properties (88). Also, according to the current data, Nano emulsion form of nettle for being neuroprotective requires lower doses when compared to the crude extract of nettle. Besides, these anti-oxidant properties demonstrated the high capability of Nano form of this herbal agent. It seems that Urtica dioica, in both aqueous extract and Nano emulsion form, can be effective on the diabetes-induced neuropathy and histopathological malicious effects by modulation of cell death and apoptosis in the sciatic nerve and can also act as an neuroprotective agent $(88,89)$. According to the current study, metformin and Cuminum cyminum $L$ essence could significantly decrease Bax, Caspase-3, and Caspase7 levels while Bcl-2 level increased. Also, it modulates STZ-induced histopathological changes, which confirm its neuroprotective properties $(90,91)$. The previous study indicated that cumin may serve as an anti-apoptosis herbal agent and may also help in attenuating diabetic complications by improving and inhibition of cell death signaling (91). Cuminum cyminum oil was observed to bring some neuroprotective effects on diabetic subjects (80). It was demonstrated that Cuminum cyminum oil may serve as a neuroprotective and anti-apoptosis compound and may also help in attenuating diabetic complications by the inhibition of cell death signaling pathways and parameters (80). Besides, it seems that some parts of the Nano emulsion of nettle beneficial effects on the management of sciatic level of the histopathological changes are mediated by the Cuminum cyminum $L$ essence, which is used inside in the Nano emulsion.

\section{Conclusion}

In this study, the emulsion was prepared using two plant materials, including nettle aqueous extract and cumin essential oil with spherical shape and nanometer scale. Additionally, in pharmacological experiments, our data indicated that the administration of nettle (Urtica dioica) aqueous extract and the Nano emulsion significantly act as a potent neuroprotective agent against STZ-induced diabetes and its sequels such as neuropathy. Of note, it seems that this effect was mediated via the modulation of oxidative stress, inflammation, apoptosis, and histopathological changes. Therefore, it can be said that the Nano emulsion can be used in special circumstances such as diabetic neuropathy. Also, it seems that some parts of the Nano emulsion of nettle beneficial effects on the management of diabetes-induced molecular and histopathological changes are mediated by the Cuminum cyminum $L$ essence, which is 
used inside in the Nano emulsion. According to our findings and the increasing rate of diabetes and other metabolic diseases among human beings, it seems that the Nano emulsion can be considered as a good candidate for the prevention of diabetes-induced neuropathy.

\section{Declarations}

All below author we claimed that there is no conflict of interest for our manuscript and agreed with submission of this manuscript to your journal.

Sara Javadi, Negar Motakef Kazemi*, Majid Motaghinejad, Amelia Seifalian

Ethics approval and consent to participate

All the authors approve ethics and consent to participate.

consent for publication

All the authors are consent to publishing.

\section{Availability of data and materials}

We agree to make the data and materials available.

\section{Competing interests}

The authors declare that they have no competing interests.

\section{Funding}

We did not receive any funding for this research.

\section{Authors' contributions}

Author contributions were as below:

Conceptualization: Majid Motaghinejad

Data curation: Sara javadi and Negar Motakef Kazmi

Formal analysis: Majid motaghinejad

Funding acquisition: Sara javadi and Negar Motakef Kazmi

Investigation and Methodology: Sara javadi and Negar Motakef Kazmi

Project administration: Majid Motaghinejad 
Resources and software: Sara javadi and Negar Motakef Kazmi

and Amelia Seifalian

Supervision: Majid Motaghinejad

Validation, Visualization, Writing - review, and editing were done by: Majid Motaghinejad and Negar Motakef Kazmi.

\section{Acknowledgements}

Not applicable.

\section{Authors' information (optional)}

This section is optional

\section{- Compliance with Ethical Standards}

\section{Disclosure of potential conflicts of interest}

There is no conflict of interest for our manuscript.

\section{Research involving Human Participants and/or Animals}

Our experimental procedure was approved by the Ethical Committee of the Islamic Azad University, Tehran central branch, Tehran, Iran, and this research was performed in terms of the Guidelines of Animal Ethics and Welfare and the guideline of Islamic Azad University in agreement with ARRIVE (Animal Research: Reporting of In Vivo Experiments) procedures. This paper was prepared from the data obtained from the master of sciences thesis and the ethical code of these two research projects were IR.IAU.PS.REC.1397.100.

\section{Informed consent}

Not applicable.

\section{References}

1. Aloulou AHK, Elloumi D, Ali MB, Hargafi K, Jaouadi B (2012) Hypoglycemic and antilipidemic properties of kombucha tea in alloxan-induced diabetic rats. BMC Complement Altern Med 12:63

2. Hunt LMAN, Akana LL (2000) Herbs, prayer, and insulin: use of medical and alternative treatments by a group of Mexican-American diabetic patients. J Fam Pract 49:216-223

3. PE W (2005) Quality of life of patients with diabetes mellitus. an overview of research in primary health care in the Nordic countries. Scand J Prim Health Care 23(2):68-74 
4. Hassan KAMMM (2017) Oral nano-emulsion of fenugreek oil for treatment of diabetes. Int J Pharm Sci Res 8(7):3151-3154

5. Ghalavand AMP, Deleramnasab M, Khodadoust M (2017) The effect of interval training and nettle supplement on glycemic control and blood pressure in men with type 2 diabetes. Int J Basic Sci Med 2(1):33-40

6. Golalipour MKV, Ghafari S, Mohammad Gharravi (2006) A Chronic Effect of the Hydroalcholic Extract of Urtica dioica Leaves on Regeneration of ß-cells of Hyperglycemic Rats. Pak J Biol Sci 9:14821485

7. Anuradha VDA (2004) Hypoglycemic effect of cinnamon and cumin seed powder on type 2 diabete. Indian $\mathrm{J}$ of Nutrition 41(9):370-374

8. Hajiashrafi S, Kazemi NM (2019) Preparation and evaluation of ZnO nanoparticles by thermal decomposition of MOF-5. Heliyon 5(9):e02152

9. Javadzadeh Y, Bahari LA (2017) Therapeutic nanostructures for dermal and transdermal drug delivery. Nano-and Microscale Drug Delivery Systems: Elsevier; p. 131 - 46

10. Anton N, Vandamme TF (2009) The universality of low-energy nano-emulsification. Int J Pharm 377(1-2):142-147

11. Sahu P, Das D, Mishra VK, Kashaw V, Kashaw SK (2017) Nanoemulsion: a novel eon in cancer chemotherapy. Mini Rev Med Chem 17(18):1778-1792

12. Sahu PDD, Mishra VK, Kashaw V, Kashaw SK (2017) Nanoemulsion: A novel eon in cancer chemotherapy. Mini- Rev Med Chem 17(18):1778-1792

13. Javadzadeh YBL (2017) In: A MG (ed) Therapeutic nanostructures for dermal and transdermal drug delivery. Elsevier, Nano-and Microscale Drug Delivery Systems Amsterdam

14. Anton NVT (2009) The universality of lowenergy nano-emulsification. Int J Pharm 377:142-147

15. Kilkenny C, Browne W, Cuthill I, Emerson M, Altram D (2010) Animal research: Reporting of in vivo experiments, National Centre for the Replacement, Refinement and Reduction of Animals in Research. Originally published in PLOS biology.

16. Santos-Nogueira E, Redondo Castro E, Mancuso R, Navarro X (2012) Randall-Selitto test: a new approach for the detection of neuropathic pain after spinal cord injury. J Neurotrauma 29(5):898904

17. Anseloni VC, Ennis M, Lidow MS (2003) Optimization of the mechanical nociceptive threshold testing with the Randall-Selitto assay. J Neurosci Methods 131(1-2):93-97

18. Bannon AW, Malmberg AB (2007) Models of nociception: hot-plate, tail-flick, and formalin tests in rodents. Curr Protoc Neurosci 41(1):8 1-8.9. 16

19. Dogrul A, Gülmez SE, Deveci MS, Gul H, Ossipov MH, Porreca F et al (2007) The local antinociceptive actions of nonsteroidal antiinflammatory drugs in the mouse radiant heat tail-flick test. Anesth Analgesia 104(4):927-935 
20. Nakamura A, Miyoshi H, Ukawa S, Nakamura K, Nakagawa T, Terauchi Y et al (2018) Serum adiponectin and insulin secretion: a direct or inverse association? J diabetes Invest 9(5):1106-1109

21. Rebholz CM, Yu B, Zheng Z, Chang P, Tin A, Köttgen A et al (2018) Serum metabolomic profile of incident diabetes. Diabetologia 61(5):1046-1054

22. Motaghinejad M, Motevalian M, Fatima S, Faraji F, Mozaffari S (2017) The Neuroprotective Effect of Curcumin Against Nicotine-Induced Neurotoxicity is Mediated by CREB-BDNF Signaling Pathway. Neurochem Res 42(10):2921-2932

23. Motaghinejad M, Motevalian M, Fatima S, Hashemi H, Gholami M (2017) Curcumin confers neuroprotection against alcohol-induced hippocampal neurodegeneration via CREB-BDNF pathway in rats. Biomed Pharmacother 87:721-740

24. Motaghinejad M, Seyedjavadein Z, Motevalian M, Asadi M (2016) The neuroprotective effect of lithium against high dose methylphenidate: possible role of BDNF. Neurotoxicology 56:40-54

25. Motaghinejad M, Karimian SM, Motaghinejad O, Shabab B, Asadighaleni M, Fatima S (2015) The effect of various morphine weaning regimens on the sequelae of opioid tolerance involving physical dependency, anxiety and hippocampus cell neurodegeneration in rats. Fundam Clin Pharmacol 29(3):299-309

26. Motaghinejad M, Motevalian M, Fatima S (2017) Mediatory role of NMDA, AMPA/kainate, GABAA and Alpha2 receptors in topiramate neuroprotective effects against methylphenidate induced neurotoxicity in rat. Life Sci 179:37-53

27. Motaghinejad M, Motevalian M, Fatima S, Beiranvand T, Mozaffari S (2017) Topiramate via NMDA, AMPA/kainate, GABAA and Alpha2 receptors and by modulation of CREB/BDNF and Akt/GSK3 signaling pathway exerts neuroprotective effects against methylphenidate-induced neurotoxicity in rats. J Neural Transm 124(11):1369-1387

28. Motaghinejad M, Motevalian M, Falak R, Heidari M, Sharzad M, Kalantari E (2016) Neuroprotective effects of various doses of topiramate against methylphenidate-induced oxidative stress and inflammation in isolated rat amygdala: the possible role of CREB/BDNF signaling pathway. J Neural Transm 123(12):1463-1477

29. Motaghinejad M, Motevalian M, Babalouei F, Abdollahi M, Heidari M, Madjd Z (2017) Possible involvement of CREB/BDNF signaling pathway in neuroprotective effects of topiramate against methylphenidate induced apoptosis, oxidative stress and inflammation in isolated hippocampus of rats: molecular, biochemical and histological evidences.Brain Research Bulletin.

30. Hadwan $\mathrm{MH}$ (2018) Simple spectrophotometric assay for measuring catalase activity in biological tissues. BMC Biochem 19(1):7

31. Motaghinejad M, Mashayekh R, Motevalian M, Safari S (2020) The possible role of CREB-BDNF signaling pathway in neuroprotective effects of minocycline against alcohol induced neurodegeneration: Molecular and behavioral evidences. Fundamental \& Clinical Pharmacology

32. Mehrafza S, Kermanshahi S, Mostafidi S, Motaghinejad M, Motevalian M, Fatima S (2019) Pharmacological evidence for lithium-induced neuroprotection against methamphetamine-induced 
neurodegeneration via Akt-1/GSK3 and CREB-BDNF signaling pathways. Iran J Basic Med Sci 22(8):856

33. Feizipour S, Sobhani S, Mehrafza S, Gholami M, Motaghinejad M, Motevalian M et al (2020) Selegiline acts as neuroprotective agent against methamphetamine-prompted mood and cognitive related behavior and neurotoxicity in rats: Involvement of CREB/BDNF and Akt/GSK3 signal pathways. Iran J Basic Med Sci 23(5):606-615

34. Nagib AM, Elsayed Matter Y, Gheith OA, Refaie AF, Othman NF, Al-Otaibi T (2019) Diabetic nephropathy following posttransplant diabetes mellitus. Exp Clin Transplant 17(2):138-146

35. Choudhury H, Pandey M, Hua CK, Mun CS, Jing JK, Kong L et al (2018) An update on natural compounds in the remedy of diabetes mellitus: A systematic review. J traditional Complement Med 8(3):361-376

36. Turton JL, Raab R, Rooney KB (2018) Low-carbohydrate diets for type 1 diabetes mellitus: A systematic review. PLoS ONE 13(3):e0194987

37. Chauhan PS, Yadav D, Tayal S, Jin J-O (2020) Therapeutic Advancements in the Management of Diabetes Mellitus with Special Reference to Nanotechnology.Current Pharmaceutical Design.

38. Di Martino P, Censi R, Rosa Gigliobianco M, Zerrillo L, Magnoni F, Agas D et al (2017) Nano-medicine improving the bioavailability of small molecules for the prevention of neurodegenerative diseases. Curr Pharm Design 23(13):1897-1908

39. Mohsen AM (2019) Nanotechnology advanced strategies for the management of diabetes mellitus. Curr Drug Targets 20(10):995-1007

40. Alhalmi A, Alzubaidi N, Abdulmalik W (2018) Current advances in nanotechnology for delivery of antidiabetic drugs: A review. Int J Pharmacogn 5:1-7

41. Rakotoarisoa M, Angelova A (2018) Amphiphilic nanocarrier systems for curcumin delivery in neurodegenerative disorders. Medicines 5(4):126

42. Kumar A, Kaur H, Singh A (2018) Neuropathic pain models caused by damage to central or peripheral nervous system. Pharmacol Rep 70(2):206-216

43. Iqbal Z, Azmi S, Yadav R, Ferdousi M, Kumar M, Cuthbertson DJ et al (2018) Diabetic peripheral neuropathy: epidemiology, diagnosis, and pharmacotherapy. Clin Ther 40(6):828-849

44. Abraham A, Barnett C, Katzberg HD, Lovblom LE, Perkins BA, Bril V (2018) Sex differences in neuropathic pain intensity in diabetes. J Neurol Sci 388:103-106

45. Namazi N, Tarighat A, Bahrami A (2012) The effect of hydro alcoholic nettle (Urtica dioica) extract on oxidative stress in patients with type 2 diabetes: a randomized double-blind clinical trial. Pak J Biol Sci 15(2):98-102

46. Namazi N, Esfanjani A, Heshmati J, Bahrami A (2011) The effect of hydro alcoholic Nettle (Urtica dioica) extracts on insulin sensitivity and some inflammatory indicators in patients with type 2 diabetes: a randomized double-blind control trial. Pakistan J Biol sciences: PJBS 14(15):775-779 
47. Das M, Sarma B, Khan A, Mosihuzzaman M, Nahar N, Ali L et al (2009) The antidiabetic and antilipidemic activity of aqueous extract of Urtica dioica L. on type2 diabetic model rats. J BioScience 17:1-6

48. Legssyer A, Ziyyat A, Mekhfi H, Bnouham M, Tahri A, Serhrouchni M et al (2002) Cardiovascular effects of Urtica dioica L. in isolated rat heart and aorta. Phytotherapy Research: An International Journal Devoted to Pharmacological and Toxicological Evaluation of Natural Product Derivatives. 16:503-5076

49. Vajic U-J, Grujic-Milanovic J, Miloradovic Z, Jovovic D, Ivanov M, Karanovic D et al (2018) Urtica dioica L. leaf extract modulates blood pressure and oxidative stress in spontaneously hypertensive rats. Phytomedicine 46:39-45

50. Wile DJ, Toth C (2010) Association of metformin, elevated homocysteine, and methylmalonic acid levels and clinically worsened diabetic peripheral neuropathy. Diabetes Care 33(1):156-161

51. Ma J, Yu H, Liu J, Chen Y, Wang Q, Xiang L (2015) Metformin attenuates hyperalgesia and allodynia in rats with painful diabetic neuropathy induced by streptozotocin. Eur J Pharmacol 764:599-606

52. Mao-Ying Q-L, Kavelaars A, Krukowski K, Huo X-J, Zhou W, Price TJ et al (2014) The anti-diabetic drug metformin protects against chemotherapy-induced peripheral neuropathy in a mouse model. PLOS ONE 9(6):e100701

53. Jagtap A, Patil P (2010) Antihyperglycemic activity and inhibition of advanced glycation end product formation by Cuminum cyminum in streptozotocin induced diabetic rats. Food Chem Toxicol 48(89):2030-2036

54. Dhandapani S, Subramanian VR, Rajagopal S, Namasivayam N (2002) Hypolipidemic effect of Cuminum cyminum L. on alloxan-induced diabetic rats. Pharmacol Res 46(3):251-255

55. Kianbakht S, Khalighi-Sigaroodi F, Dabaghian FH (2013) Improved glycemic control in patients with advanced type 2 diabetes mellitus taking Urtica dioica leaf extract: a randomized double-blind placebo-controlled clinical trial. Clin Lab 59(9-10):1071-1076

56. Haghju S, Beigzadeh S, Almasi H, Hamishehkar H (2016) Chitosan films incorporated with nettle (Urtica dioica L.) extract-loaded nanoliposomes: I. Physicochemical characterisation and antimicrobial properties. J Microencapsul 33(5):438-448

57. Mnif S, Aifa S (2015) Cumin (Cuminum cyminum L.) from traditional uses to potential biomedical applications. Chem Biodivers 12(5):733-742

58. Cosentino F, Assenza GE (2004) Diabetes and inflammation. Herz 29(8):749-759

59. Lontchi-Yimagou E, Sobngwi E, Matsha TE, Kengne AP (2013) Diabetes mellitus and inflammation. Curr Diab Rep 13(3):435-444

60. Raz I, Eldor R, Naparstek Y (2005) Immune modulation for prevention of type 1 diabetes mellitus. Trends Biotechnol 23(3):128-134

61. Tahri A, Yamani S, Legssyer A, Aziz M, Mekhfi H, Bnouham M et al (2000) Acute diuretic, natriuretic and hypotensive effects of a continuous perfusion of aqueous extract of Urtica dioica in the rat. $J$ Ethnopharmacol 73(1-2):95-100 
62. Dar SA, Yousuf A, Ganai FA, Sharma P, Kumar N, Singh R (2012) Bioassay guided isolation and identification of anti-inflammatory and anti-microbial compounds from Urtica dioica L.(Urticaceae) leaves. Afr J Biotechnol 11(65):12910-12920

63. Joshi BC, Mukhija M, Kalia AN (2014) Pharmacognostical review of Urtica dioica L.International Journal of Green Pharmacy (IJGP). ; 8(4)

64. Cameron AR, Morrison VL, Levin D, Mohan M, Forteath C, Beall C et al (2016) Anti-inflammatory effects of metformin irrespective of diabetes status. Circul Res 119(5):652-665

65. Kang N, Yuan R, Huang L, Liu Z, Huang D, Huang L et al (2019) Atypical Nitrogen-Containing Flavonoid in the Fruits of Cumin (Cuminum cyminum L.) with Anti-inflammatory Activity. J Agric Food Chem 67(30):8339-8347

66. Matteucci E, Giampietro 0 (2000) Oxidative stress in families of type 1 diabetic patients. Diabetes Care 23(8):1182-1186

67. Ceriello A, Bortolotti N, Motz E, Crescentini A, Lizzio S, Russo A et al (1998) Meal-generated oxidative stress in type 2 diabetic patients. Diabetes Care 21(9):1529-1533

68. Vessby J, Basu S, Mohsen R, Berne C, Vessby B (2002) Oxidative stress and antioxidant status in type 1 diabetes mellitus. J Intern Med 251(1):69-76

69. Asmat U, Abad K, Ismail K (2016) Diabetes mellitus and oxidative stress-A concise review. Saudi Pharm J 24(5):547-553

70. Matough FA, Budin SB, Hamid ZA, Alwahaibi N, Mohamed J (2012) The role of oxidative stress and antioxidants in diabetic complications. Sultan Qaboos University Medical Journal 12(1):5

71. Ceriello A, Testa R, Genovese S (2016) Clinical implications of oxidative stress and potential role of natural antioxidants in diabetic vascular complications. Nutr Metabolism Cardiovasc Dis 26(4):285292

72. Negi G, Kumar A, Sharma SS (2011) Melatonin modulates neuroinflammation and oxidative stress in experimental diabetic neuropathy: effects on NF-KB and Nrf2 cascades. J Pineal Res 50(2):124-131

73. Shokrzadeh M, Mirshafa A, Yekta Moghaddam N, Birjandian B, Shaki F (2018) Mitochondrial dysfunction contribute to diabetic neurotoxicity induced by streptozocin in mice: protective effect of Urtica dioica and pioglitazone. Toxicol Mech Methods 28(7):499-506

74. Gülçin I, Küfrevioğlu Öi, Oktay M, Büyükokuroğlu ME (2004) Antioxidant, antimicrobial, antiulcer and analgesic activities of nettle (Urtica dioica L.). J Ethnopharmacol 90(2-3):205-215

75. Patel SS, Udayabanu M (2013) Effect of Urtica dioica on memory dysfunction and hypoalgesia in an experimental model of diabetic neuropathy. Neurosci Lett 552:114-119

76. Shokrzadeh M, Sadat-Hosseini S, Fallah M, Shaki F (2017) Synergism effects of pioglitazone and Urtica dioica extract in streptozotocin-induced nephropathy via attenuation of oxidative stress. Iran J basic Med Sci 20(5):497

77. Singh G, Marimuthu P, Lampasona Md, Catalan CA (2006) Cuminum cyminum L. Chemical constituents, antioxidant and antifungal studies on its volatile oil and acetone extract. Indian 
Perfumer 50(3):31-39

78. El-Ghorab AH, Nauman M, Anjum FM, Hussain S, Nadeem M (2010) A comparative study on chemical composition and antioxidant activity of ginger (Zingiber officinale) and cumin (Cuminum cyminum). J Agric Food Chem 58(14):8231-8237

79. Al-Snafi AE (2016) The pharmacological activities of Cuminum cyminum-A review. IOSR J Pharm $6(6): 46-65$

80. Srinivasan K (2018) Cumin (Cuminum cyminum) and black cumin (Nigella sativa) seeds: traditional uses, chemical constituents, and nutraceutical effects. Food Qual Saf 2(1):1-16

81. Singh RP, Gangadharappa H, Mruthunjaya K (2017) Cuminum cyminum-A popular spice: An updated review.Pharmacognosy Journal. ; 9(3)

82. Al-Shabrawey M, Smith S (2010) Prediction of diabetic retinopathy: role of oxidative stress and relevance of apoptotic biomarkers. EPMA J 1(1):56-72

83. Allen DA, Yaqoob MM, Harwood SM (2005) Mechanisms of high glucose-induced apoptosis and its relationship to diabetic complications. J Nutr Biochem 16(12):705-713

84. Srinivasan S, Stevens M, Wiley JW (2000) Diabetic peripheral neuropathy: evidence for apoptosis and associated mitochondrial dysfunction. Diabetes 49(11):1932-1938

85. Schmeichel AM, Schmelzer JD, Low PA (2003) Oxidative injury and apoptosis of dorsal root ganglion neurons in chronic experimental diabetic neuropathy. Diabetes 52(1):165-171

86. Sifuentes-Franco S, Padilla-Tejeda DE, Carrillo-lbarra S, Miranda-Díaz AG (2018) Oxidative stress, apoptosis, and mitochondrial function in diabetic nephropathy. International Journal of Endocrinology. ;2018

87. Gutowska I, Jakubczyk K, Dec K, Baranowska-Bosiacka I, Drozd A, Janda K et al (2014) Effect of the extract from nettle (Urtica dioica L.) fruit cluster on the synthesis of pro-inflammatory agents in hepatocytes treated with fluoride. Fluoride 47(2):109-118

88. Patel SS, Ray R, Sharma A, Mehta V, Katyal A, Udayabanu M (2018) Antidepressant and anxiolytic like effects of Urtica dioica leaves in streptozotocin induced diabetic mice. Metab Brain Dis 33(4):1281-1292

89. Golalipour MJ, Jahanshahi M, Ghafari S, Afshar M (2013) The preventive and treatment effect of Urtica dioica on astrocyte density in the CA1 and CA3 subfields of hippocampus in STZ induced diabetic rats. Int J Morphology 31(2):693-699

90. Jayasudha A (2011) Anti-urolithiatic and Antioxidant activity of fruit extract of Cuminum cyminum linn in rats. RGUHS

91. Morshedi D, Kesejini TS, Aliakbari F, Karami-Osboo R, Shakibaei M, Marvian AT et al (2014) Identification and characterization of a compound from Cuminum cyminum essential oil with antifibrilation and cytotoxic effect. Res Pharm Sci 9(6):431

\section{Tables}


Table-1: Percentages of the nanoemulsions materials

\begin{tabular}{|llll|}
\hline Sample number & Nettle aqueous extract & Cumin essential oil & Tween80 \\
\hline 1 & $94 \%$ & $4 \%$ & $2 \%$ \\
\hline 2 & $95 \%$ & $4 \%$ & $1 \%$ \\
\hline 3 & $96 \%$ & $2 \%$ & $2 \%$ \\
\hline
\end{tabular}

Table -2: Effects of nettle (Urtica dioica) hydro-alcoholic extract (50,100 and $200 \mathrm{mg} / \mathrm{kg}$, i.p.), nettle Nanoemulsion (25, 50 and $100 \mathrm{mg} / \mathrm{kg}$, i.p.) and Cuminum cyminum L essence ( $4 \mathrm{mg} / \mathrm{kg}$, i.p.) $\mathrm{GSH}$ and GSSG content in STZ treated rats

\begin{tabular}{|c|c|c|c|}
\hline Group & $\begin{array}{l}\text { Mean } \pm \text { SEM } \\
\text { GSH (nmol/mg } \\
\text { protein) }\end{array}$ & $\begin{array}{l}\text { GSSG (nmol/mg } \\
\text { protein) }\end{array}$ & GSH/GSSG \\
\hline Control group & $115.4 \pm 8.6$ & $1.55 \pm 0.6$ & 74 \\
\hline STZ (65 mg/kg) & $26.8 \pm 7.5^{a}$ & $19.4 \pm 2.1^{\mathrm{a}}$ & $1.4^{\mathrm{a}}$ \\
\hline $\begin{array}{l}\mathrm{STZ}+\text { Nettle Extract( } 50 \\
\mathrm{mg} / \mathrm{kg})\end{array}$ & $45.9 \pm 5.1^{b}$ & $15.3 \pm 1.1^{b}$ & $3.2^{b}$ \\
\hline $\begin{array}{l}\text { STZ + Nettle Extract(100 } \\
\mathrm{mg} / \mathrm{kg})\end{array}$ & $56.8 \pm 8.2^{b}$ & $12.4 \pm 1.3^{b}$ & $4.5^{b}$ \\
\hline $\begin{array}{l}\text { STZ + Nettle Extract( } 200 \\
\mathrm{mg} / \mathrm{kg})\end{array}$ & $62.2 \pm 6.2^{b}$ & $11.0 \pm 0.8^{b}$ & $5.6^{b}$ \\
\hline STZ + Nettle NE $(25 \mathrm{mg} / \mathrm{kg})$ & $58.5 \pm 8.5^{b}$ & $13.5 \pm 1.9^{b}$ & $2.1^{\mathrm{b}}$ \\
\hline STZ + Nettle NE (50 mg/kg) & $79.8 \pm 9.3^{b}$ & $9.3 \pm 1.0^{b}$ & $8.5^{b}$ \\
\hline STZ + Nettle NE (100 mg/kg) & $88.8 \pm 7.1^{b}$ & $7.5 \pm 1.2^{b}$ & $11.4^{b}$ \\
\hline STZ + MET (150 mg/kg) & $105.5 \pm 8.2^{b}$ & $4.2 \pm 0.7^{b}$ & $25.11^{b}$ \\
\hline STZ + CC essence (4 mg/kg) & $64.8 \pm 8.6^{b}$ & $8.3 \pm 0.9^{b}$ & $7.8^{b}$ \\
\hline
\end{tabular}

All data are presented as mean \pm SEM, $n=10$.
a $\mathrm{P}<0.001$ vs control
b $\mathrm{P}<0.001$ vs group treated with STZ $(65 \mathrm{mg} / \mathrm{kg})$ only.

STZ: Streptozosin, Nettle Extract: nettle (Urtica dioica) hydro-alcoholic extract, Nettle NE; nettle Nanoemulsion, MET: metformin, CC essence: Cuminum cyminum L essence. 
Figures
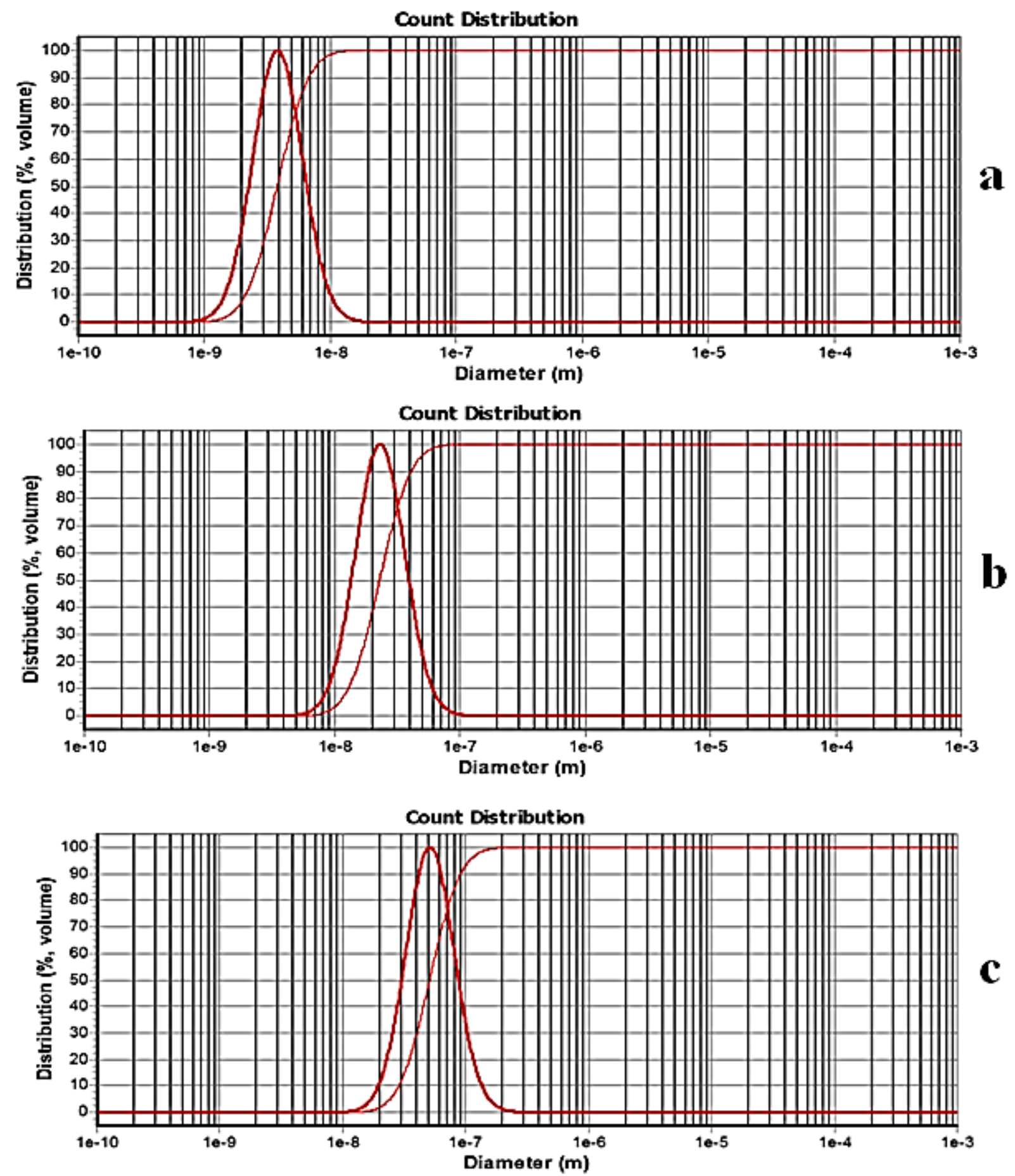

Figure 1

Dynamic light scattering of the Nettle nanoemulsion with (a) $94 \%$, (b) $95 \%$, and (c) $96 \%$ of Nettle aqueous extract. 



Figure 2

(a) TEM images of the Nettle nanoemulsion and (b) particle size distribution histogram. 


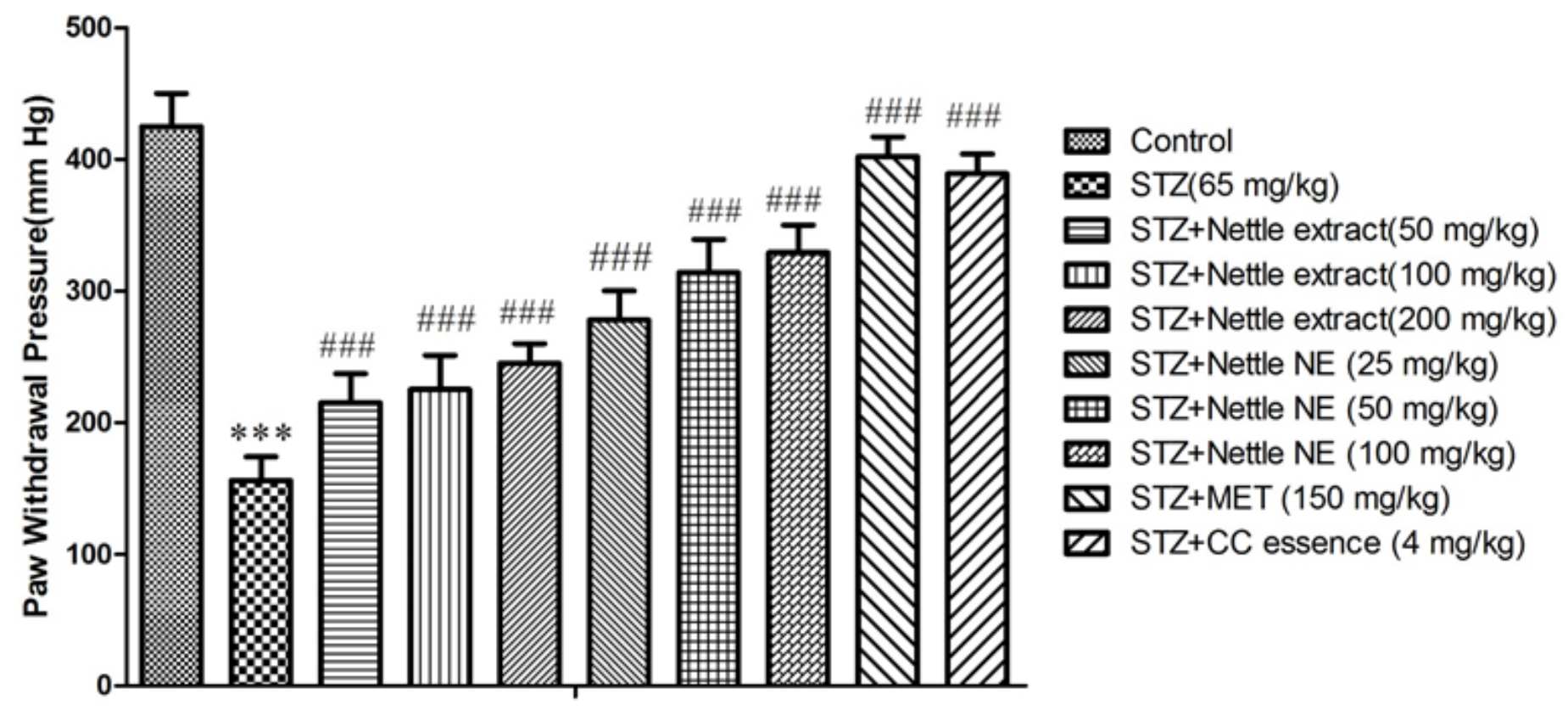

Groups

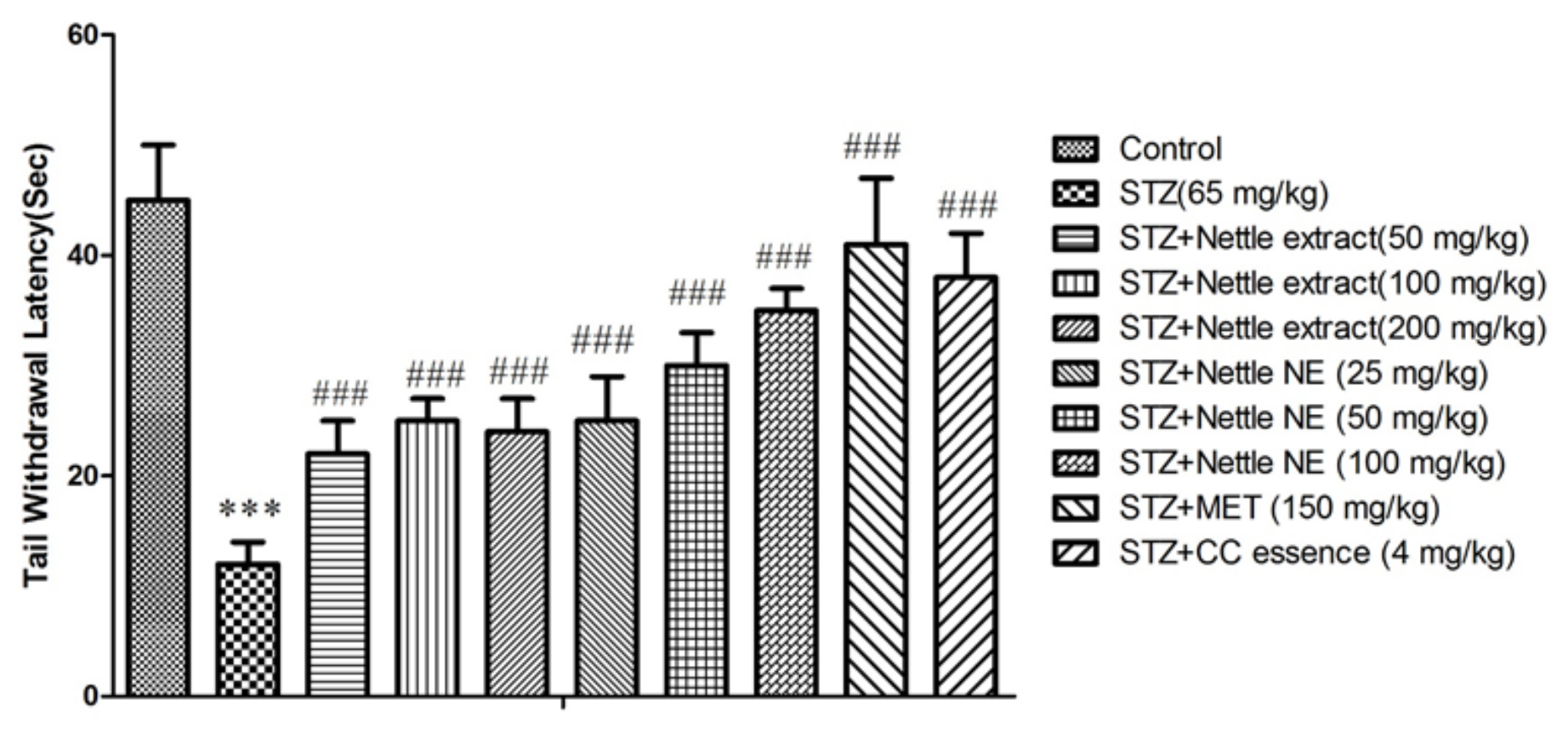

Groups

Figure 3

Effects of nettle (Urtica dioica) hydro-alcoholic extract (50,100 and $200 \mathrm{mg} / \mathrm{kg}$, i.p.), nettle Nanoemulsion $(25,50$ and $100 \mathrm{mg} / \mathrm{kg}$, i.p.) and Cuminum cyminum L essence (4 mg/kg, i.p.) in paw withdrawal pressure (A) and tail withdrawal latency (B) in STZ induced diabetic rat .

All data are expressed as Mean \pm SEM $(n=10)$. 
*** $P<0.001$ vs control

\#\#\# P< 0.001 vs group treated with STZ $(65 \mathrm{mg} / \mathrm{kg})$ only.

STZ: Streptozosin, Nettle Extract: nettle (Urtica dioica) hydro-alcoholic extract, Nettle NE; nettle Nanoemulsion, MET: metformin, CC essence: Cuminum cyminum L essence

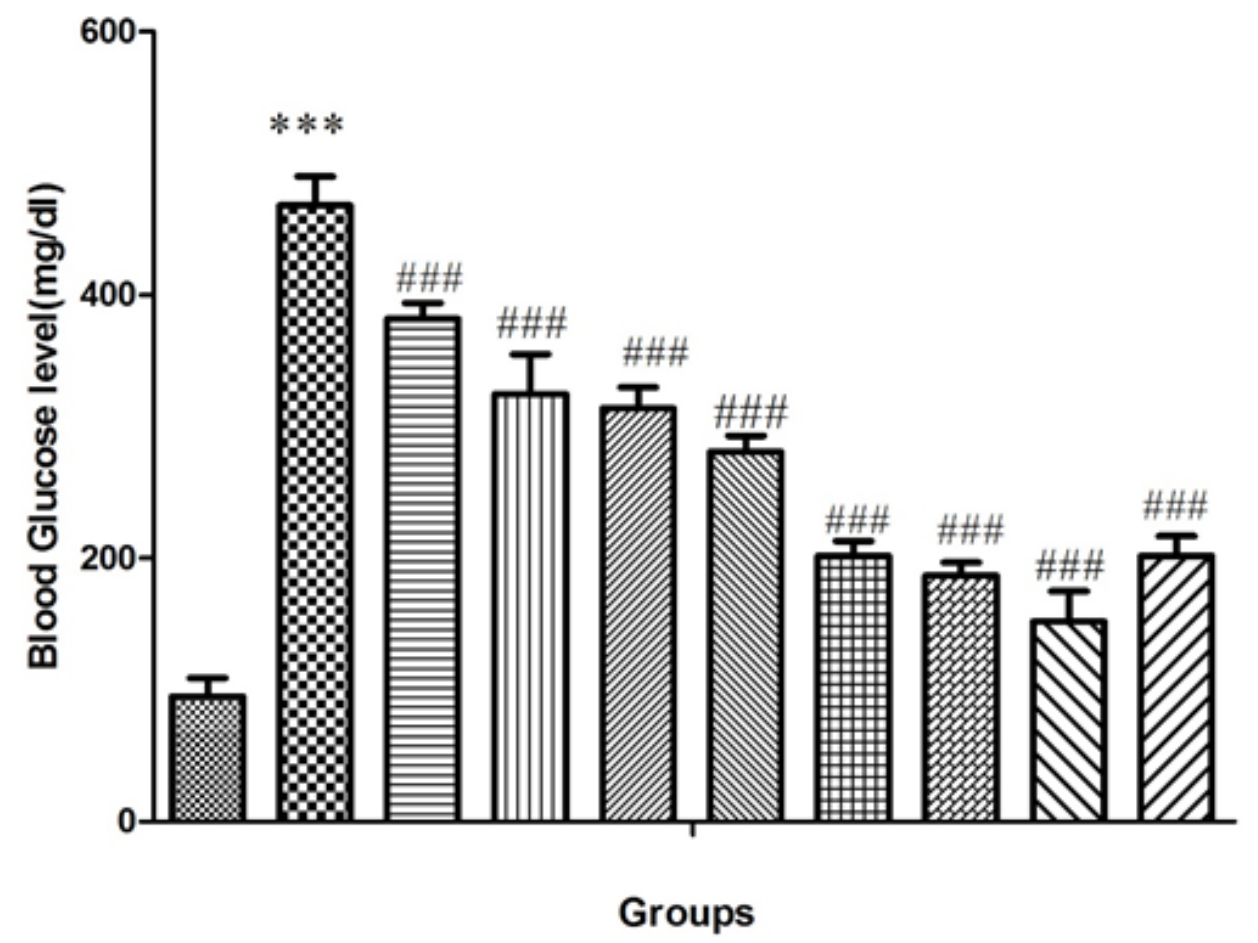
Control
$\mathrm{STZ}(65 \mathrm{mg} / \mathrm{kg})$
回 STZ+Nettle extract $(50 \mathrm{mg} / \mathrm{kg})$
血 STZ+Nettle extract(100 mg/kg)
III STZ+Nettle extract $(200 \mathrm{mg} / \mathrm{kg})$
and ST+Nettle NE $(25 \mathrm{mg} / \mathrm{kg})$
曲 STZ+Nettle NE $(50 \mathrm{mg} / \mathrm{kg})$
STZ+Nettle NE $(100 \mathrm{mg} / \mathrm{kg})$
$\square \mathrm{STZ}+\mathrm{MET}(150 \mathrm{mg} / \mathrm{kg})$
ש STZ+CC essence $(4 \mathrm{mg} / \mathrm{kg})$

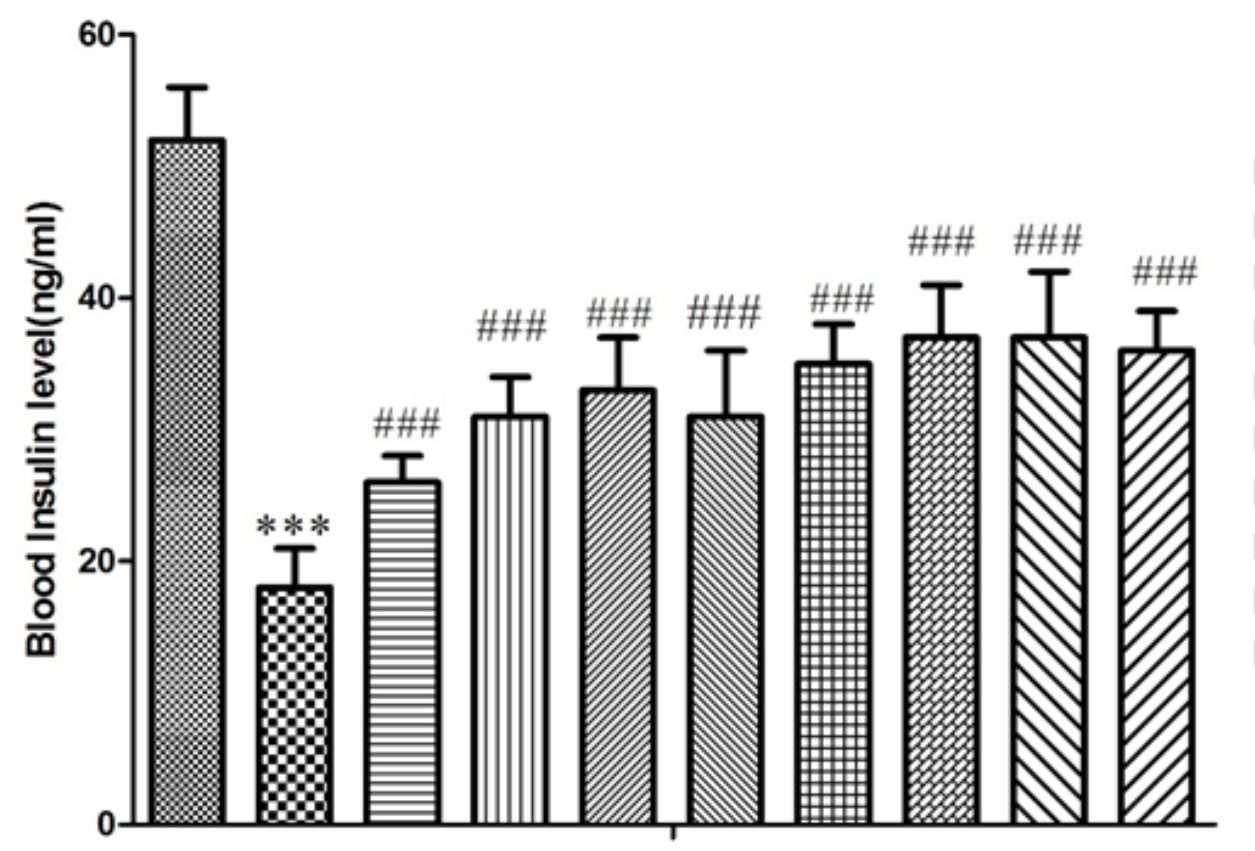

m Control

$\$ \mathrm{STZ}(65 \mathrm{mg} / \mathrm{kg}$ )

曰 STZ+Nettle extract $(50 \mathrm{mg} / \mathrm{kg})$

亚 STZ+Nettle extract $(100 \mathrm{mg} / \mathrm{kg}$ )

III STZ+Nettle extract(200 mg/kg)

STIZ+Nettle NE $(25 \mathrm{mg} / \mathrm{kg})$

曲 STZ+Nettle NE $(50 \mathrm{mg} / \mathrm{kg})$

STZ+Nettle NE $(100 \mathrm{mg} / \mathrm{kg})$

$\triangle \mathrm{STZ}+\mathrm{MET}(150 \mathrm{mg} / \mathrm{kg}$ )

ש STZ+CC essence $(4 \mathrm{mg} / \mathrm{kg})$

Groups 
Figure 4

Effects of nettle (Urtica dioica) hydro-alcoholic extract (50,100 and $200 \mathrm{mg} / \mathrm{kg}$, i.p.), nettle Nanoemulsion (25, 50 and $100 \mathrm{mg} / \mathrm{kg}$, i.p.) and Cuminum cyminum L essence (4 mg/kg, i.p.) in blood glucose level (A) and Blood insulin level (B) in STZ induced diabetic rat .

All data are expressed as Mean \pm SEM $(n=10)$.

$\star \star \star P<0.001$ vs control

\#\#\# P< 0.001 vs group treated with STZ $(65 \mathrm{mg} / \mathrm{kg})$ only.

STZ: Streptozosin, Nettle Extract: nettle (Urtica dioica) hydro-alcoholic extract, Nettle NE; nettle Nanoemulsion, MET: metformin, CC essence: Cuminum cyminum L essence
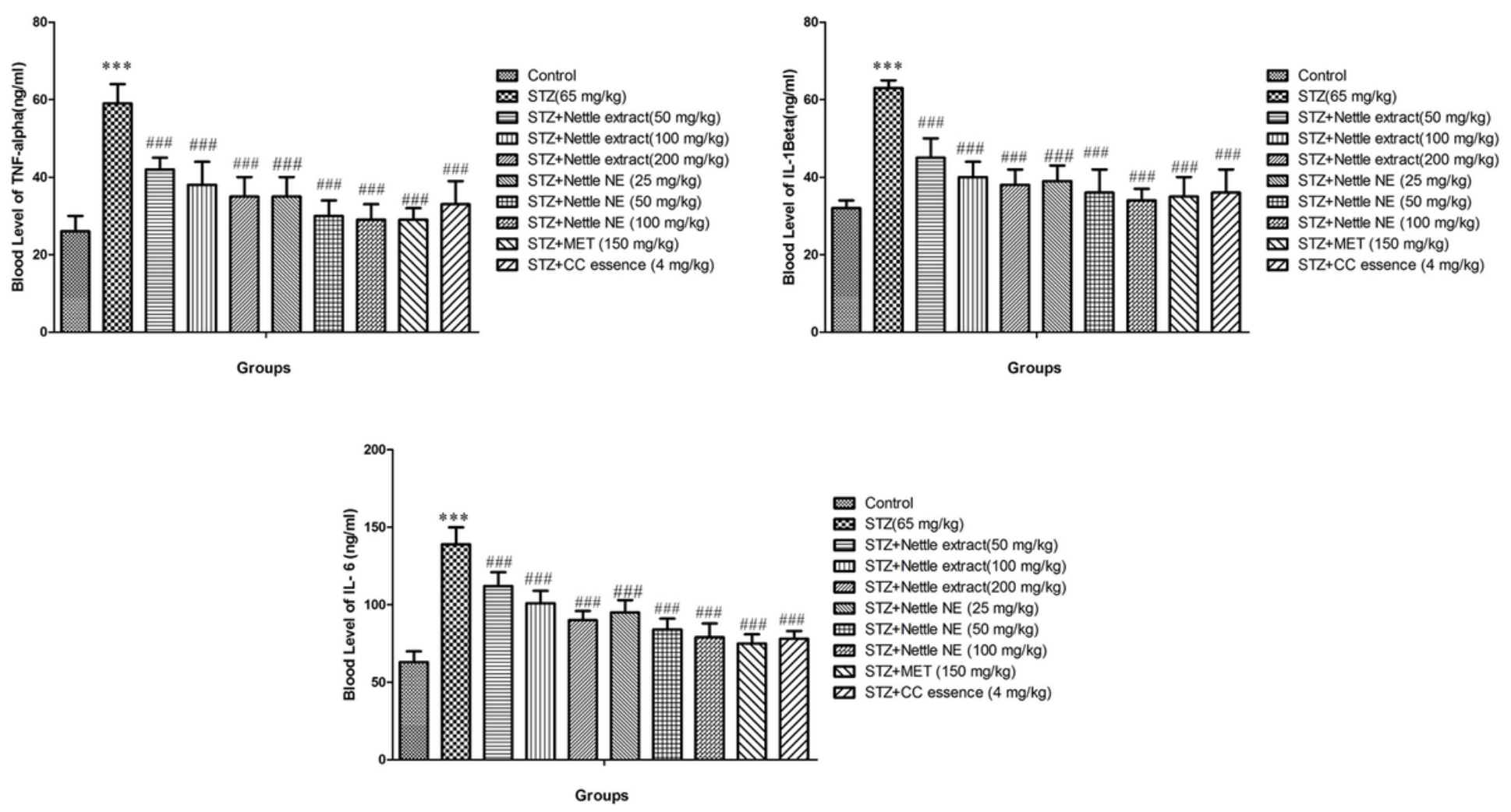

Figure 5

Effects of nettle (Urtica dioica) hydro-alcoholic extract (50,100 and $200 \mathrm{mg} / \mathrm{kg}$, i.p.), nettle Nanoemulsion $(25,50$ and $100 \mathrm{mg} / \mathrm{kg}$, i.p.) and Cuminum cyminum L essence (4 mg/kg, i.p.) in blood level of TNF-a (A) ,IL-1 $\beta$ (B) and IL-6 (C) in STZ induced diabetic rat .

All data are expressed as Mean $\pm \operatorname{SEM}(n=10)$. 
$\star \star \star P<0.001$ vs control

\#\#\# P< 0.001 vs group treated with STZ (65 mg/kg) only.

STZ: Streptozosin, Nettle Extract: nettle (Urtica dioica) hydro-alcoholic extract, Nettle NE; nettle Nanoemulsion, MET: metformin, CC essence: Cuminum cyminum L essence
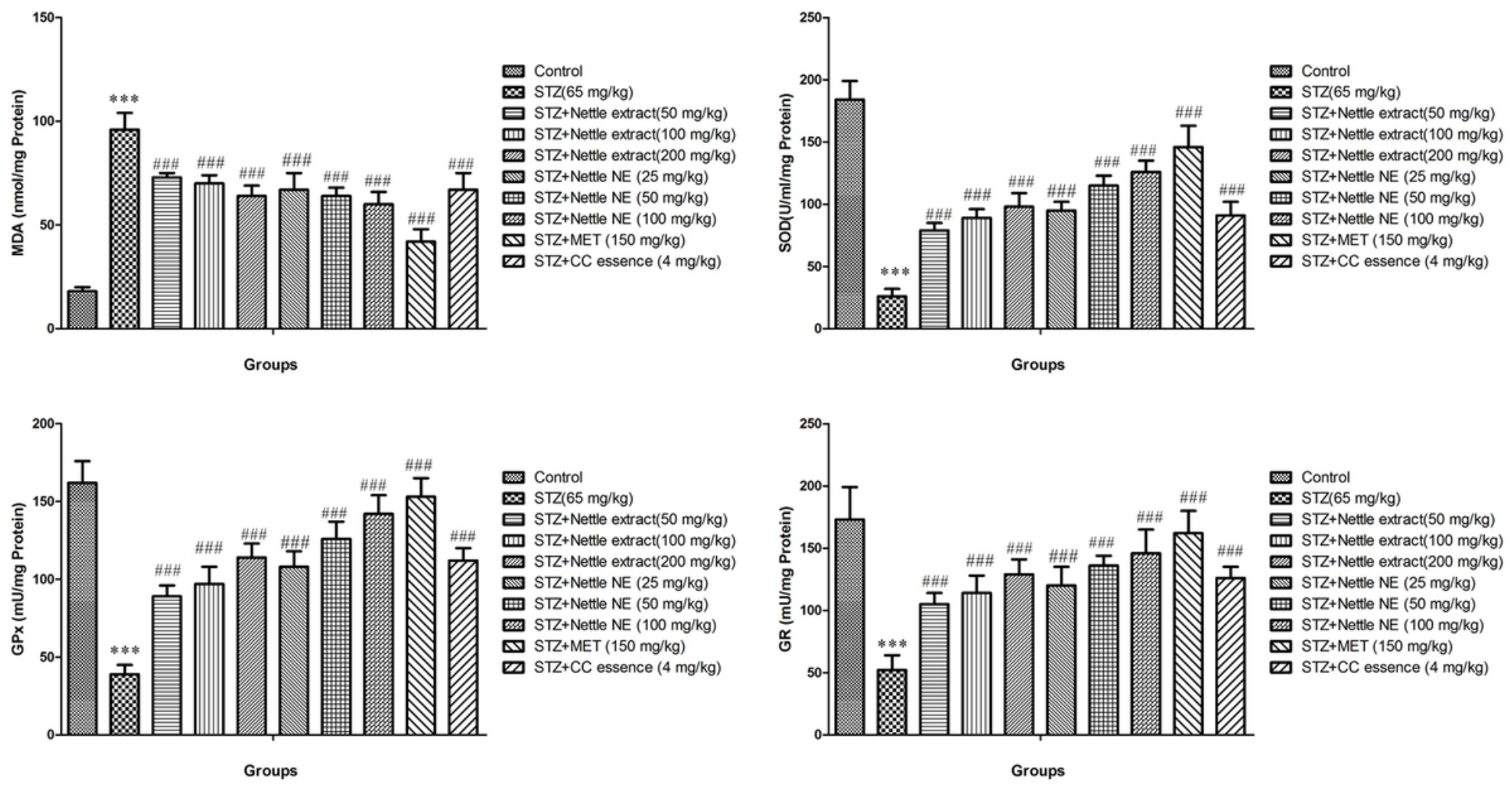

Figure 6

Effects of nettle (Urtica dioica) hydro-alcoholic extract (50,100 and $200 \mathrm{mg} / \mathrm{kg}$, i.p.), nettle Nanoemulsion (25, 50 and $100 \mathrm{mg} / \mathrm{kg}$, i.p.) and Cuminum cyminum L essence (4 mg/kg, i.p.) in sciatic level of lipid peroxidation (A), and activity of SOD (B), GPx (C) and GR (D) in in sciatic nerve of STZ induced diabetic rat .

All data are expressed as Mean \pm SEM $(n=10)$.

$\star \star \star P<0.001$ vs control

\#\#\# P< 0.001 vs group treated with STZ $(65 \mathrm{mg} / \mathrm{kg})$ only.

STZ: Streptozosin, Nettle Extract: nettle (Urtica dioica) hydro-alcoholic extract, Nettle NE; nettle Nanoemulsion, MET: metformin, CC essence: Cuminum cyminum L essence 


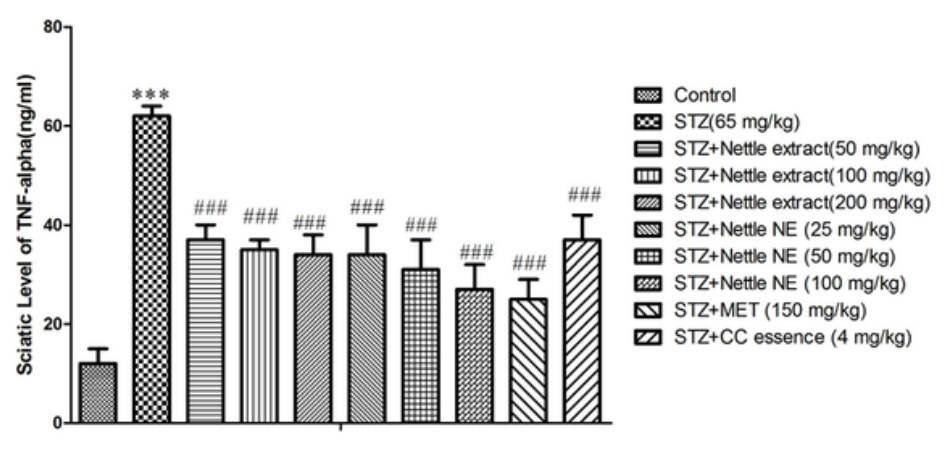

Groups
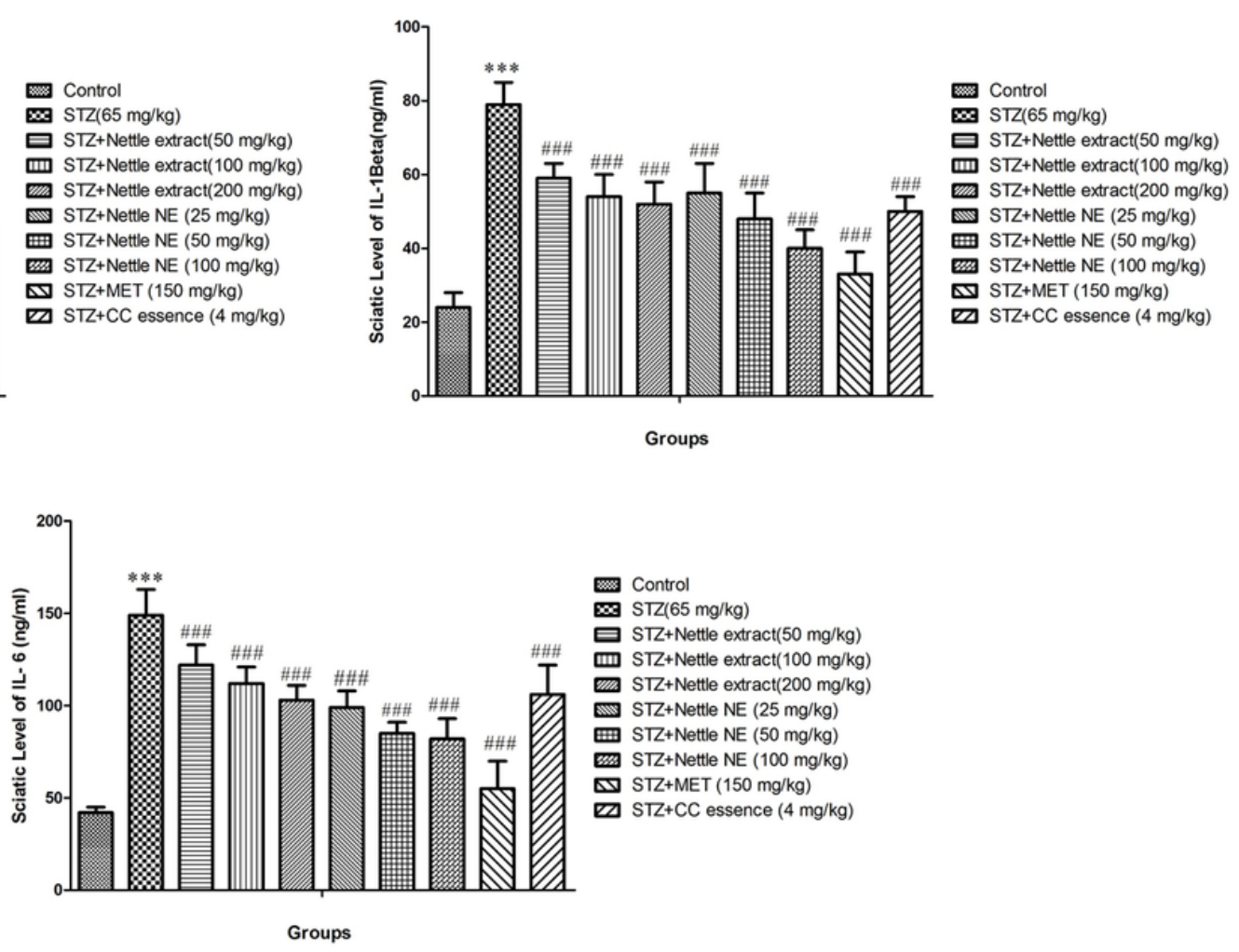

Figure 7

Effects of nettle (Urtica dioica) hydro-alcoholic extract (50,100 and $200 \mathrm{mg} / \mathrm{kg}$, i.p.), nettle Nanoemulsion $(25,50$ and $100 \mathrm{mg} / \mathrm{kg}$, i.p.) and Cuminum cyminum L essence (4 mg/kg, i.p.) in sciatic level of TNF-a (A) ,IL-1 $\beta$ (B) and IL-6 (C) in STZ induced diabetic rat .

All data are expressed as Mean \pm SEM $(n=10)$.

$\star \star \star P<0.001$ vs control

\#\#\# $\mathrm{P}<0.001$ vs group treated with STZ $(65 \mathrm{mg} / \mathrm{kg})$ only.

STZ: Streptozosin, Nettle Extract: nettle (Urtica dioica) hydro-alcoholic extract, Nettle NE; nettle Nanoemulsion, MET: metformin, CC essence: Cuminum cyminum L essence 

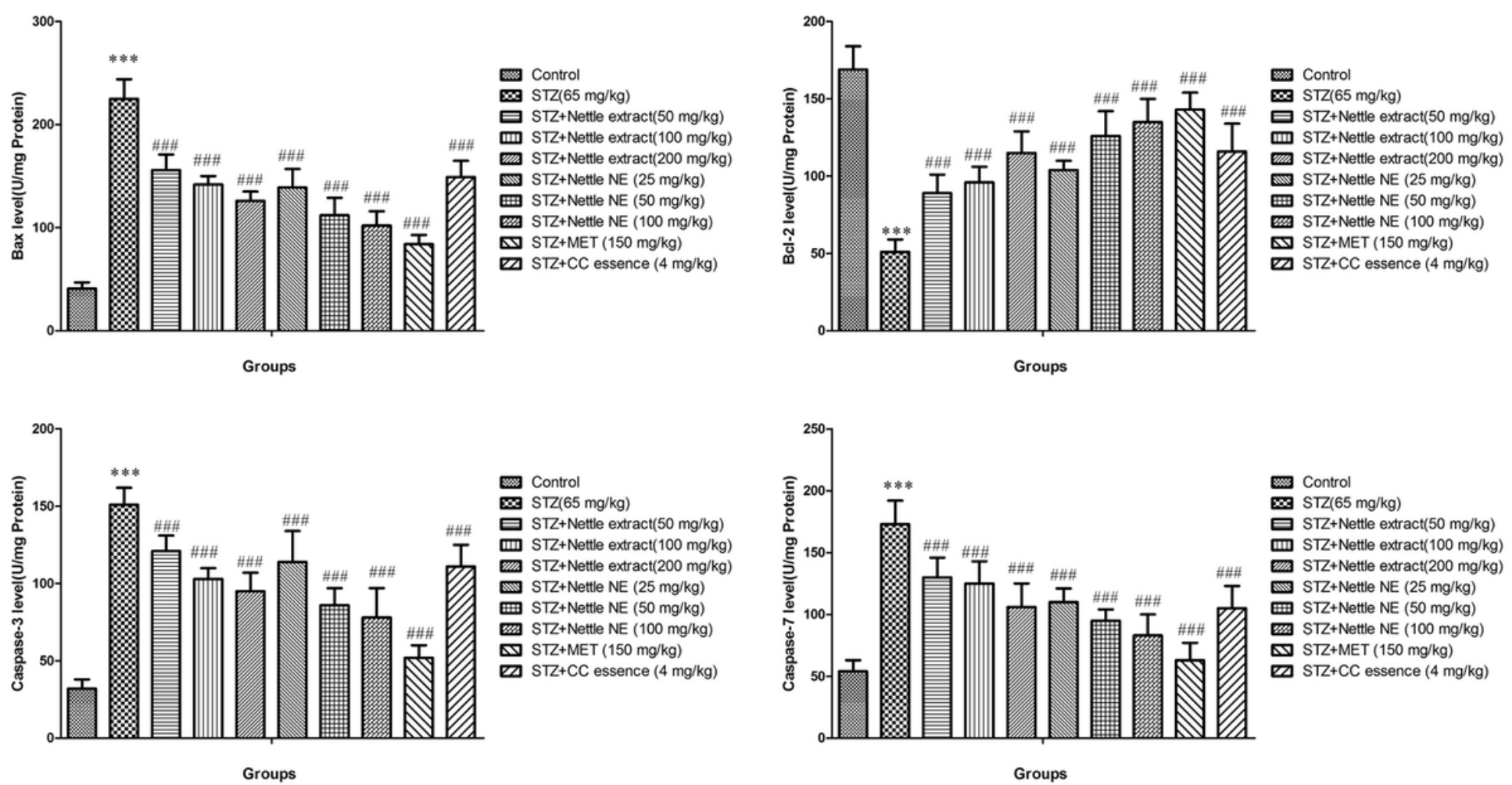

Figure 8

Effects of nettle (Urtica dioica) hydro-alcoholic extract (50,100 and $200 \mathrm{mg} / \mathrm{kg}$, i.p.), nettle Nanoemulsion (25, 50 and $100 \mathrm{mg} / \mathrm{kg}$, i.p.) and Cuminum cyminum L essence (4 mg/kg, i.p.) in sciatic level of Bax (A) ,Bcl-2 (B) , caspase-3 (C) and caspase-7(D) in STZ induced diabetic rat .

All data are expressed as Mean \pm SEM $(n=10)$.

$\star \star \star P<0.001$ vs control

\#\#\# $\mathrm{P}<0.001$ vs group treated with STZ $(65 \mathrm{mg} / \mathrm{kg})$ only.

STZ: Streptozosin, Nettle Extract: nettle (Urtica dioica) hydro-alcoholic extract, Nettle NE; nettle Nanoemulsion, MET: metformin, CC essence: Cuminum cyminum L essence
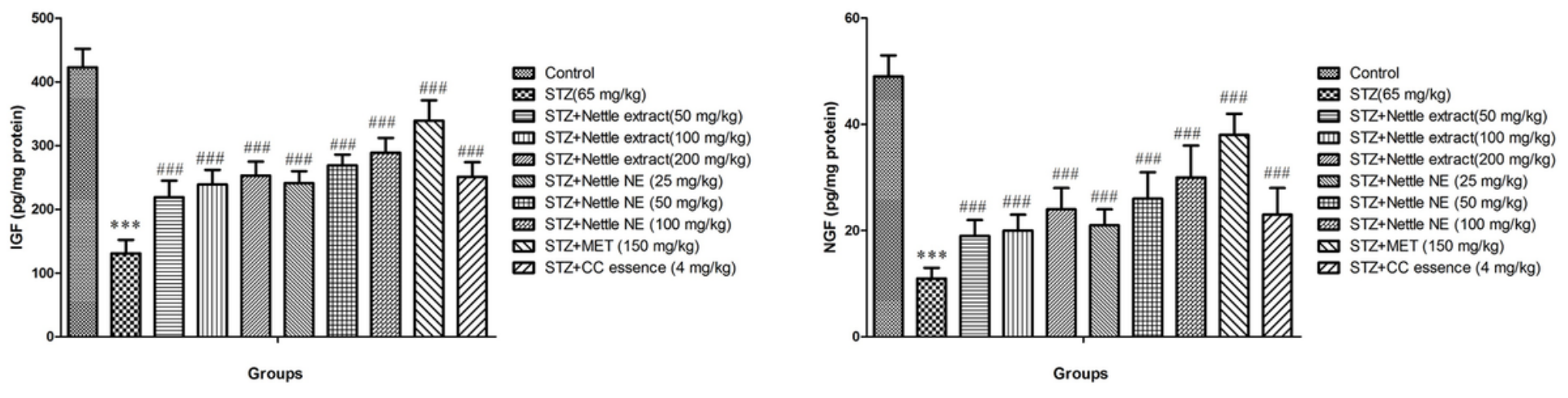


\section{Figure 9}

Effects of nettle (Urtica dioica) hydro-alcoholic extract (50,100 and $200 \mathrm{mg} / \mathrm{kg}$, i.p.), nettle Nanoemulsion (25, 50 and $100 \mathrm{mg} / \mathrm{kg}$, i.p.) and Cuminum cyminum L essence (4 mg/kg, i.p.) in sciatic level of IGF(A) and NGF (B) in STZ induced diabetic rat .

All data are expressed as Mean \pm SEM $(n=10)$.

$\star \star \star * P<0.001$ vs control

\#\#\# P< 0.001 vs group treated with STZ $(65 \mathrm{mg} / \mathrm{kg})$ only.

STZ: Streptozosin, Nettle Extract: nettle (Urtica dioica) hydro-alcoholic extract, Nettle NE; nettle Nanoemulsion, MET: metformin, CC essence: Cuminum cyminum L essence. 


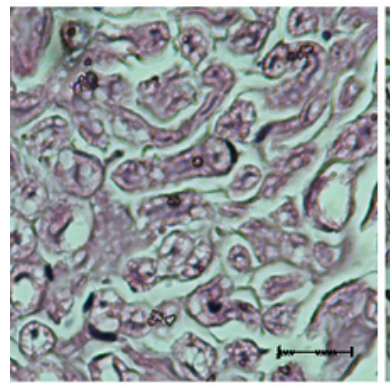

(C)

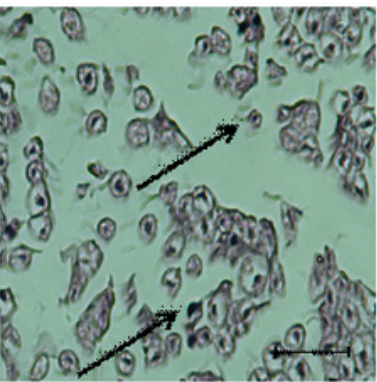

(D)

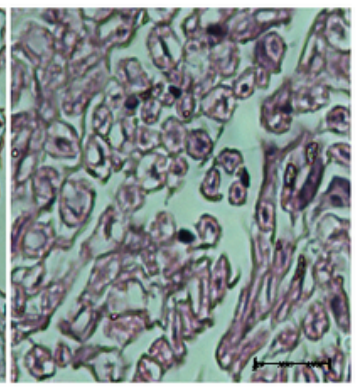

(E)

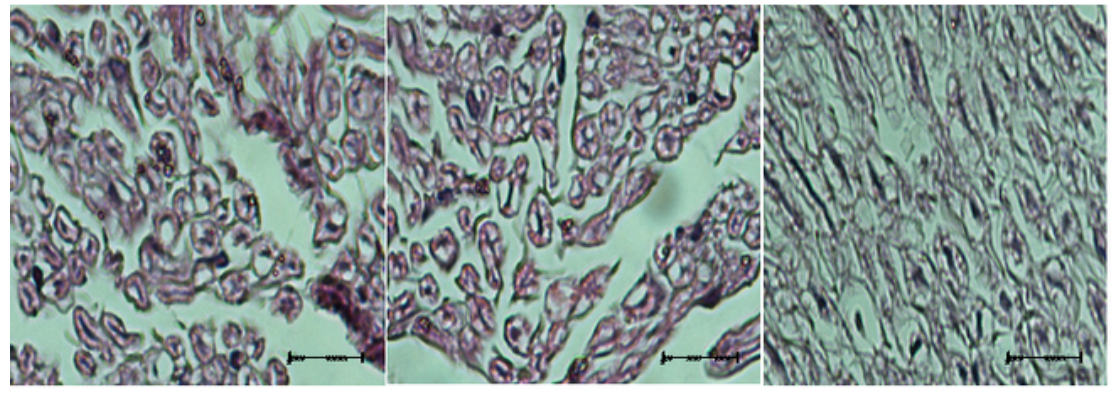

(F)

(G)

(H)

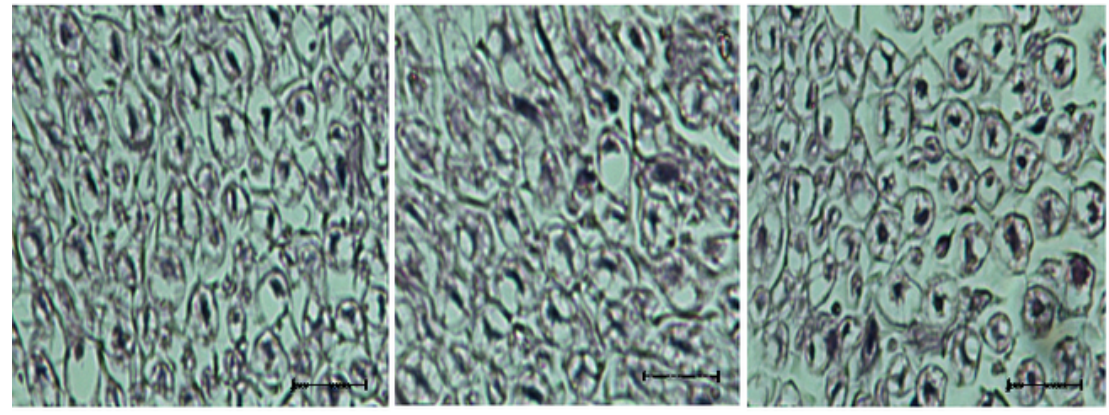

(I)

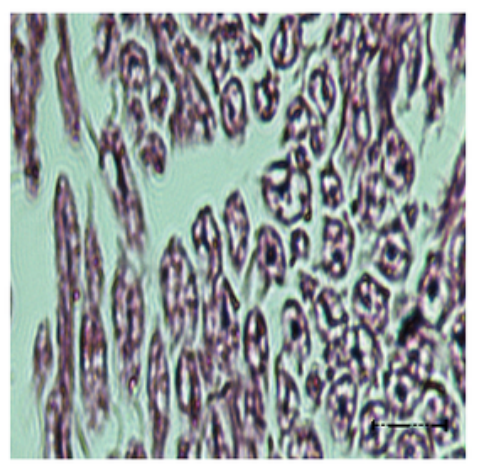

Figure 10

Representative images of Hematoxylin and Eosin-stained of sciatic nerve. Control group (A), STZ (65 $\mathrm{mg} / \mathrm{kg}$ ) (B) and STZ in combination with nettle (Urtica dioica) hydro-alcoholic extract (50,100 and 200 $\mathrm{mg} / \mathrm{kg}$, i.p.)(C,D and E respectively) , STZ in combination with nettle Nanoemulsion (25, 50 and 100 $\mathrm{mg} / \mathrm{kg}$, i.p.)(F, G and $\mathrm{H}$ respectively) and also STZ in combination with Cuminum cyminum $\mathrm{L}$ essence (4 
$\mathrm{mg} / \mathrm{kg}$, i.p.)(I), and STZ in combination with metformin $(150 \mathrm{mg} . / \mathrm{kg})(\mathrm{J})$. Arrows indicate the vacuolation and neuronal degeneration in sciatic nerve (Magnification x400. Scale bar $100 \mu \mathrm{m}$ ). 